\title{
Chemical Synthesis and Molecular Recognition of Phosphatase- Resistant Analogues of Phosphatidylinositol-3-phosphate
}

\author{
Yong Xu ${ }^{1}$, Stephanie A. Lee ${ }^{2}$, Tatiana G. Kutateladze $^{2}$, Diego Sbrissa ${ }^{3}$, Assia Shisheva $^{3}$, and \\ Glenn D. Prestwich ${ }^{1, *}$ \\ 1 Department of Medicinal Chemistry, The University of Utah, 419 Wakara Way, Suite 205, Salt Lake City, \\ Utah 84108-1257 USA \\ 2 Department of Pharmacology, University of Colorado Health Sciences Center, Aurora, CO 80045 USA \\ 3 Department of Physiology, Wayne State University School of Medicine, 540 E. Canfield Detroit, MI 48201 \\ USA
}

\section{Abstract}

The remodeling of phosphatidylinositol polyphosphates in cellular membranes by phosphatases and kinases orchestrates the signaling by these lipids in space and time. In order to provide chemical tools to study of the changes in cell physiology mediated by these lipids, three new metabolically-stabilized (ms) analogues of phosphatidylinositol-3-phosphate (PtdIns(3)P were synthesized. We describe herein the total asymmetric synthesis of 3-methylphosphonate, 3-monofluoromethylphosphonate and 3-phosphorothioate analogues of PtdIns(3)P. From differentially protected D-myo-inositol key intermediates, a versatile phosphoramidite reagent was employed in the synthesis of PtdIns(3)P analogues with diacylglyceryl moieties containing dioleoyl, dipalmitoyl and dibutyryl chains. In addition, we introduce a new phosphorlyation reagent, monofluoromethylphosphonyl chloride, which has general applications for the preparation of "pKa-matched" monofluorophosphonates. These ms-PtdIns(3)P analogues exhibited reduced binding activities with ${ }^{15} \mathrm{~N}$-labelled FYVE and PX domains, as significant ${ }^{1} \mathrm{H}$ and ${ }^{15} \mathrm{~N}$ chemical shift changes in the FYVE domain were induced by titrating ms-PtdIns(3)Ps into membrane-mimetic dodecylphosphocholine (DPC) micelles. In addition, the PtdIns(3)P analogues with dioleyl and dipalmitoyl chains were substrates for the 5kinase enzyme PIKfyve; the corresponding phosphorylated ms-PI $(3,5) \mathrm{P}_{2}$ products were detected by radio-TLC analysis.

\section{Introduction}

Phosphoinositide $\left(\operatorname{PtdIns}_{n}\right)$ signaling networks are dynamically modulated by proteins with lipid recognition motifs as well as kinase, phosphatase, and phospholipase enzymatic activities. Lipid-protein interactions form the cornerstone for many signaling pathways, and the new discipline of functional lipidomics ${ }^{1}$ is defining many new targets for therapeutic interaction. ${ }^{2}$ It is now accepted that 3-phosphorylated PtdIns $\mathrm{P}_{\mathrm{n}}$ lipids -- PtdIns(3)P, PtdIns(3,4) $\mathrm{P}_{2}$, PtdIns $(3,5) \mathrm{P}_{2}$, and PtdIns $(3,4,5) \mathrm{P}_{3}$-- are intracellular signals in mammalian cells. ${ }^{3}$ These signaling lipids have been implicated as activators of protein kinase $\mathrm{C}$ isoforms, and are putative messengers in cellular signal cascades pertinent to inflammation, cell proliferation, transformation, protein kinesis, and cytoskeletal assembly. ${ }^{4,5}$

PtdIns(3)P is produced by the action of phosphoinositide-3-kinase (PI 3-K $)^{3,6}$ on PtdIns, and has cognate binding proteins, kinase and phosphatases that are important in cell physiology. 
The PI 3-K family of enzymes is an important therapeutic target for prevention of cancer, inflammation, allergy, thrombosis, and autoimmune disorders. ${ }^{5,7-11} \mathrm{PtdIns(3)P} \mathrm{is} \mathrm{also} \mathrm{a}$ substrate for PIKfyve, a 5-kinase required for endomembrane integrity and the formation of multivesicular bodies. ${ }^{12}$ PtdIns(3)P binds FYVE domains, 13,14 and is thus an important player in phagocytosis 15 and the biochemistry of vesicular trafficking of proteins. ${ }^{16} \mathrm{PX}$ domains also bind PtdIns(3)P with high affinity, and their spatiotemporal changes mediate important aspects of cell respiration and physiology. ${ }^{17}$ The 3-phosphatase myotubularin (MTM) and MTM-related (MTMR) proteins ${ }^{18}$ have been identified as important PtdIns(3)P phosphatases that contribute to lipid remodeling and are commonly mutated in genetic diseases. 19 Very recently, PtdIns(3)P phosphatase activity was observed for SapM, a Mycobacterium tuberculosis enzyme required for bacterial viability and inhibition of host cell phagolysosome biogenesis. ${ }^{20}$ In order to gain deeper insights into these biological pathways, selective reagents that could block binding, inhibit enzyme activity, activate lipid-protein mediate pathways, or act as alternative substrates would be highly desirable. To-date, 3-modified PtdIns(3)P analogues with these properties have not been reported.

In order to create metabolically-stabilized analogues of lysophosphatidic acid (LPA), we prepared two kinds of phosphatase-resistant moieties -- fluoromethylenephosphonates ${ }^{21,22}$ and phosphorothioates 23 -- which were found to be receptor sub-type specific agonists. These two functional groups have second $\mathrm{pKa}$ values that are matched to the normal phosphomonoester pKa value of 6.5. ${ }^{24}$ Phosphonate esters have been used extensively to stabilize naturally-occurring phosphates, replacing the bridging oxygen or one of the phosphate oxygens with a methylene or methyl group. The resulting analogues were less susceptible to either acidic or enzymatic cleavage. Methylphosphonates have been studied as metabolicallystable phosphate mimics, potential enzyme inhibitors, and as probes for the elucidation of biochemical processes, ${ }^{25}$ but these analogues have significantly higher second pKa values than the native phosphate group. Herein we describe the asymmetric total synthesis of methylphosphonate, fluoromethylphosphonate, and phosphorothioate analogues of PtdIns(3) P phosphatase-resistant analogues of PtdIns(3)P. The utility of these analogues in cellular, molecular, and structural biology will be described in due course.

\section{Results and Discussion}

\section{Chemical Synthesis of Phosphatase-Resistant Analogues of Phosphatidylinositol-3- phosphate}

Several strategies have been employed for total asymmetric synthesis of phosphoinositides. One approach is the use of enantiopure natural precursors, e.g., D-glucose, ${ }^{26-30}$ L-chiroinositol derivatives, ${ }^{31}$ and quinic acid. ${ }^{32-34}$ Kinetic resolution or desymmetrization via enantioselective enzymatic acylations and non-enzymatic phosphorylation of protected myoinositol derivatives is another common strategy. ${ }^{35-38}$ The separation of diastereomeric derivatives of myo-inositol with chiral auxiliaries is also used in many synthetic routes. ${ }^{39}$ ${ }^{41}$ In our early work, we developed the synthesis of enantiomerically-pure PtdIns $P_{n}$ and a variety of derivatives from D-glucose via the Ferrier rearrangement. ${ }^{28,41}$ In this paper, we have employed the more atom-efficient production of the enantiomeric inositol derivatives via the resolution of myo-inositol by crystallization of diastereomeric D-camphor ketals. ${ }^{40}$

Each of the phosphorylated phosphatidylinositols synthesized in this work employed the simple and elegant protection scheme developed by Bruzik. ${ }^{40}$ The inositol 1-position was silylated with the TBDPS group, the phosphomonoester 3-position was protected as a benzoate group, and all the remaining hydroxyl groups were protected as methoxymethyl (MOM)-ethers. In this way, 1-O-(tert-butyldiphenylsilyl)-2,4,5,6-O-tetrakis(methoxymethylene)-myo-inositol was synthesized from myo-inositol in six steps. ${ }^{40}$ 
The phosphonochloridates derived from simple phosphonic acid alkyl esters are reliable and readily accessible reagents for the phosphonylation of alcohols to produce the corresponding phosphonates. ${ }^{42,43}$ ( $O, O$-Dimethyl) methylphosphonyl chloride can be readily prepared from the corresponding methylphosphonate by chlorination with $\mathrm{PCl}_{5}$ at room temperature (rt). ${ }^{44}$

To prepare methyl fluoromethylphosphonate, we first tried N-F "electrophilic" fluorinating agents to fluorinate dimethyl methylphosphonate 10. The commercially-available fluorinating agents $N$-fluoro-1,4-diazabicyclooctane bis(tetrafluoroborate) (F-TEDA-BF 4 ) and $N$ -

fluorobenzenesulfonimide (NFSI) were chosen for investigation. ${ }^{45}$ A number of procedures for deprotonation of methylphosphonate, and its subsequent monofluorination, were evaluated. The only positive result was obtained using F-TEDA-BF 4 in anhydrous THF solvent to fluorinate the sodium enolate, but the product yields were too low (5\%) to be practical. Thus, as illustrated in Scheme 3, we developed a new method to prepare methyl

fluoromethylphosphonic chloride $\mathbf{9}$.

Dimethyl hydroxymethylphosphonate $\mathbf{6}$ was prepared in quantitative yield by the reaction of dimethyl phosphite with paraformaldehdye and anhydrous potassium carbonate in methanol. ${ }^{46}$ Direct fluorination of 6 with DAST at $-78^{\circ} \mathrm{C}$ gave a low yield (5\%). In contrast, activation of the alcohol $\mathbf{6}$ as triflate 7 (with 2,6-lutidine as base), followed by nucleophilic displacement with tetra-butylammonium fluoride (TBAF) in THF proved to be a safe and simple route to the protected monofluoromethylphosphonate $8 .{ }^{47}$ Direct chlorination of dialkyl phosphonate with oxalyl chloride ${ }^{48}$ was unsuccessful. However, a two-step protocol was successful. Thus, aminolysis of $\mathbf{8}$ with tert-butyl amine afforded the desired phosphonic acid monomethyl ester tert-butylamine salt in quantitative yield. ${ }^{43}$ The tert-butylamine salt was then converted to the free monomethyl phosphonic acid by passage through a Dowex ${ }^{\circledR}$ acidic resin. The monomethyl phosphonate was then treated with oxalyl chloride and catalytic DMF in $\mathrm{CH}_{2} \mathrm{Cl}_{2}$ initially at $0^{\circ}$ $\mathrm{C}$, followed by stirring for $2 \mathrm{~h}$ at rt. ${ }^{49}$ Analysis of a reaction aliquot by ${ }^{31} \mathrm{P}$ NMR demonstrated complete conversion. Concentration in vacuo eliminated the volatile reagents and left the desired phosphonochloridate $\mathbf{9}$ as an oily yellow residue. The product was then used without further purification, as attempts at vacuum distillation resulted in decomposition.

Returning to the inositol ring intermediates, the secondary alcohol $\mathbf{1 0}$ was phosphorylated with methyl (fluoromethyl)phosphonyl chloride in the presence of $t$-BuOK and gave the protected 3-(fluoromethyl)phosphonate 11a in good yield (46-48\%). Using amine bases commonly employed for this type of reaction, e.g., triethylamine and $\mathrm{N}$-methylimidazole, resulted in poorer yields. The silyl group in the 1-position was removed with the neutral reagent TBAFHOAc, and the resulting alcohols 11 were treated with one of the three diacylglyceryl phosphoramidite reagents 19a-19c in the presence of tetrazole followed by mild oxidation with $n-\mathrm{Bu}_{4} \mathrm{NIO}_{4}$ to give the fully protected PtdIns(3)P derivatives 14. Using the mild oxidation reagent $n-\mathrm{Bu}_{4} \mathrm{NIO}_{4}$ avoided the undesired epoxidation of the oleic acyl double bond.

To preparate the PtdIns(3)P diesters, different phosphoramidites with preattached long, medium, and short diacyl chains were prepared (Scheme 5). For evaluation in different biological and biophysical systems, we prepared the dioleoyl, dipalmitoyl, and dibutyryl reagents. Following our previously reported procedures, the 3-O-PMB-sn-(2R)-glycerol was esterified with various fatty acids using DCC/DMAP to give compounds in high yields. 26 Oxidative removal of the PMB protective group with DDQ gave the corresponding 1,2-diacyl$s n$-(2S)-glycerols in good yields without significant acyl migration. Although the 1,2-diacyl$s n$-(2S)-glycerol was reasonably stable, slow purification on silica gel facilitated acyl chain migration. Therefore, rapid flash chromatography was essential to obtain homogeneous 1,2diacyl-sn-(2S)-glycerols without acyl migration. Finally, coupling these alcohols with methyl $\mathrm{N}, \mathrm{N}$-diisopropylchlorophosphoramidite and cyanoethyl $\mathrm{N}, \mathrm{N}$ -

diisopropylchlorophosphoramidite gave phosphorylation reagents $\mathbf{1 9}$ and $\mathbf{2 0}$ in high yields. 
The removal of protective groups from the phosphate and hydroxyl of the fully-protected inositol lipid intermediates was performed as follows. First, TMSBr was used to deprotect the phosphate methyl esters. ${ }^{40}$ The fully protected derivatives were dissolved in TMSBr and $\mathrm{CH}_{2} \mathrm{Cl}_{2}(1: 1, \mathrm{v}: \mathrm{v})$ under strictly anhydrous conditions, and stirred at $\mathrm{rt}$ for $1 \mathrm{~h}$. After concentration in vacuo, the residue was dissolved in a methanol-water mixture (95:5, v:v), and then stirred for an additional $30 \mathrm{~min}$ to hydrolyze the silyl phosphate esters. After completely drying the reaction mixture in vacuo, ethanethiol was added to remove all MOM groups and provide the final products in $>98 \%$ purity. 40

The reported methods of preparation of phosphorothioates vary considerably. Some methods that are suitable for specific compounds utilize conditions that would preclude application to the synthesis of derivatives bearing more labile functional groups. For example, methyl and ethyl esters have often been used as protecting groups; deprotection is then accomplished with TMSI or TMSBr. However, this approach fails to give practical yields with phosphonothioate or phosphorothioate derivatives. ${ }^{50}$ Deprotection of the dibenzyl esters of phosphonothioic acids has been achieved with sodium in liquid ammonia ${ }^{51}$ but we sought milder reaction conditions. We turned to the cyanoethyl ester (CE), which is widely used for the synthesis of phosphonothioate or phosphorothioate acids. The CE group can be deprotected under mild basic conditions. ${ }^{23,52}$ Primary, secondary, and tertiary amine, e.g., triethylamine and $t$ butylamine, will readily remove the CE protection from phosphates and phosphorothioates at rt.

Alcohol 10 was then phosphorylated employing phosphoramidite methodology. The resulting phosphoramidite triester was oxidized with elemental sulfur to yield the corresponding phosphorothioate triester. TBAF was frequently used to deprotect the TBDPS protective group. However, we found TBAF not only removed the TBDPS ether, but simultaneously removed the CE group, despite the fact that the TBAF reagent had been neutralized with 1 equiv of acetic acid. Apparently the basicity of TBAF was sufficient to cleave the CE phosphate linkage. Thus, to selectively deprotect the TBDPS group, we selected the HF- pyridine complex, which in Py-THF solution selectively removed the TBDPS ether. This deprotection reaction was very slow, and required three weeks to reach completion. Importantly, the reaction was conducted in a Teflon container. The reaction did not occur in common glassware, which was damaged in the process. The reaction rate could not be increased without also accelerating side reactions. Finally, TASF (tris(dimethylamino)sulfonium difluorotrimethylsilicate) was also explored for this deprotection ${ }^{50,53}$, but TASF was unable to cleave the secondary alcohol silyl ether $\mathbf{2 1}$.

Three phosphoramidite reagents 20a-20c were prepared by the reaction of 2-cyanoethyl- $N, N$ diisopropylchlorophosphoramidite with diacylglycerol preattached with different acyl chains using $N, N$-diisopropylethylamine (DIPEA) as the base. ${ }^{54}$ The air-sensitive phosphoramidites were purified by rapid flash chromatography using a basic solvent system. The phosphoramidites were then condensed with secondary alcohol 22 in the presence of $1 \mathrm{H}$ tetrazole to yield the phosphoramidite intermediates.

Oxidation of phosphoramidite triester proved to be problematic. The commonly used oxidation reagents, including MCPBA, $n$ - $\mathrm{Bu}_{4} \mathrm{NIO}_{4}$ and $\mathrm{H}_{2} \mathrm{O}_{2}$, oxidized both the phosphoramidite triester and the 3-position phosphorothioate, even at low temperatures $\left(-78^{\circ} \mathrm{C}\right.$ to $\left.-20^{\circ} \mathrm{C}\right)$. Indeed, the phosphorothioate is readily oxidized to the corresponding phosphate when exposed to standard oxidation reagents. Therefore, a mild oxidation reagent was required to selectively oxidize the phosphoramidite triester without overoxidation of the phosphorothioate. Recently, $t$-BuOOSi $\left(\mathrm{CH}_{3}\right)_{3}$ and $t$-BuOOH have been utilized to selectively oxidize phosphoramidite triesters. 55 , 56 Using $t$-BuOOH gave complete oxidation of the phosphoramidite triester to phosphate without overoxidation of the phosphorothioate. The CE groups on the phosphorothioate were removed by using triethylamine (TEA) plus bistrifluoromethylsilylacetamide (BTFSA) in 
anhydrous acetonitrile. ${ }^{52}$ BTFSA was added to prevent the phosphorothioate anion from undergoing re-alkylation. The cleavage of the $O$-silyl derivatives was achieved by aqueous hydrolysis at neutral $\mathrm{pH}$ to give the MOM ether-protected intermediate. The MOM groups were removed using ethanethiol- $\mathrm{BF}_{3}$ at rt to give the final products. ${ }^{57}$

Consistent with the analytical TLC behavior of these molecules, each of the final amphiphilic ms-PtdIns(3)P derivatives could be purified by conventional chromatography using a $\mathrm{CHCl}_{3}$ $\mathrm{MeOH}-\mathrm{NH}_{4} \mathrm{OH}$ solvent system on silica gel. ${ }^{58}$ The ${ }^{1} \mathrm{H}$ NMR of the PtdIns(3)P analogues illustrated the curious solubility of these compounds and the intrinsic difficulty in obtaining high-quality NMR spectroscopic data. ${ }^{27}$ Only broad, poorly resolved ${ }^{1} \mathrm{H}$ NMR resonances could be detected in the single-solvent systems $\mathrm{CDCl}_{3}$ or $\mathrm{CD}_{3} \mathrm{OD}$. In contrast, in $\left(\mathrm{CDCl}_{3}\right.$ $\mathrm{CD}_{3} \mathrm{OD}, 3: 2$, v:v), the ${ }^{1} \mathrm{H}$ NMR resonances for the head group and acyl chains were well resolved.

\section{Binding to FYVE and PX Domains}

In cellular membranes, PtdIns(3)P is specifically recognized by a number of protein binding partners including FYVE and PX domains. ${ }^{14,59}$ To test whether the PtdIns(3)P analogues are able to bind the physiological targets, we investigated interactions of human EEA1 FYVE and yeast Vam7 PX domains by NMR spectroscopy. Significant ${ }^{1} \mathrm{H}$ and ${ }^{15} \mathrm{~N}$ chemical shift changes in the FYVE domain were induced by titrating $\mathrm{C}_{16}$-PtdIns(3) $\mathrm{P}_{-} \mathrm{CH}_{2} \mathrm{~F}$ 16 $\mathbf{b}$ embedded in membrane-mimetic dodecylphosphocholine (DPC) micelles (Fig. 1A). These perturbations paralleled chemical shift changes seen in the FYVE domain as $\mathrm{C}_{4}$-PtdIns(3)P-enriched DPC micelles were titrated in (Fig. 1B). Thus the PtdIns(3)P analog and unmodified lipid are accommodated by the same binding pocket consisting of four Arg and two His residues of the FYVE domain. ${ }^{59}$ However, the resonance perturbations observed during PtdIns(3) $\mathrm{P}_{-} \mathrm{CH}_{2} \mathrm{~F}$ titration were smaller in magnitude indicating weaker binding. These results reveal the importance of two negatively charged oxygen atoms of the 3-phosphate group of PtdIns(3)P and their hydrogen bonding potential for the strong anchoring of the inositol ring by the basic residues of the FYVE domain. Similarly, when the PX domain was treated with PtdIns(3)P$\mathrm{CH}_{2} \mathrm{~F} \mathrm{16b}(\mathbf{c})$ which was pre-bound to the mixed diheptanoyl phosphatidylcholine (DHPC)/ CHAPS micelles, the observed chemical shift changes mirrored those seen upon binding of unmodified PtdIns(3)P. Addition of PtdIns(3)P(S) 24b(c) and PtdIns(3)P-CH $\mathrm{CH}_{3}$ 15b(c) lipids or titrating the soluble $\mathrm{C}_{4}$ - forms of PtdIns(3)P analogs resulted in considerably smaller chemical shift changes in ${ }^{1} \mathrm{H}_{-}-{ }^{15} \mathrm{~N}$ HSQC spectra of the proteins, although the pattern of resonance perturbations remained essentially unchanged (Fig. 1C,D and data not shown).

\section{PIKfyve uses ms-Ptdlns(3)P analogs as substrates}

PtdIns(3,5)-P $\mathrm{P}_{2}$ and PtdIns(5)-P could be produced in vitro by two mammalian enzymes: type I PIP kinase ${ }^{60}$ and PIKfyve. ${ }^{61}$ Genetic and biochemical evidence has recently accumulated to implicate PIKfyve as the principal enzyme responsible for their biosynthesis in the cellular context. ${ }^{62}$ We now provide evidence for specific and high affinity interactions between the PIKfyve and metabolically-stabilized analogues of PtdIns(3)P in vitro. PIKfyve activity was assayed as described previously by the $\gamma_{-}{ }^{32} \mathrm{P}$-ATP-dependent phosphorylation of PtdIns. It was found that each of the three PtdIns(3)P analogues having dioleyl and dipalmitoyl chains were substrates for the kinase PIKfyve, as phosphorylated products were detected by radio-TLC analysis (Figure 2). Since (monofluoro)methyl phosphonate and phosphorothioate are less polar than the phosphate group, the resulting $5-{ }^{32} \mathrm{P}-\mathrm{ms}-\mathrm{Ptd} \operatorname{In}(3,5) \mathrm{P}_{2}$ analogues migrated faster than the unmodified 5- ${ }^{32} \mathrm{P}-\operatorname{PtdIns}(3,5) \mathrm{P}_{2}$ (Figure 2). Thus, the stabilized phosphorothioate and phosphonate groups at the 3-position of these PtdIns(3)P analogues are recognized by the nonclassical FYVE motif within the PIKfyve catalytic domain. 63 


\section{Conclusions}

In summary, we have developed a general approach to the synthesis of methylphosphonate, monofluoromethylphosphonate and phosphorothioate analogues of PtdIns(3)P. This strategy also is applicable to the synthesis of analogues of all other PtdInsP ${ }_{n}$ and $\operatorname{InsP}_{n}$. In addition, our method enables synthesis of both saturated and unsaturated acyl analogues of PtdInsP $P_{n}$. These $\mathrm{PI}(3) \mathrm{P}$ analogues exhibited reduced binding activities with ${ }^{15} \mathrm{~N}$-labeled FYVE and PX domains as significant ${ }^{1} \mathrm{H}$ and ${ }^{15} \mathrm{~N}$ chemical shift changes in the FYVE domain were induced by titrating ms-PtdIns(3)P in membrane-mimetic dodecylphosphocholine (DPC) micelles. In addition, these PtdIns(3)P analogues with dioleyl and dipalmitoyl chains were recognized by PIKfyve, as phosphorylated ms-PtdIns $(3,5) \mathrm{P}_{2}$ products were detected by radio-TLC analysis. The metabolically-stabilized analogues of PtdIns(3)P reported herein provide new tools for the elucidation of the roles of these phosphoinositide monophosphates in cell signaling. Specific applications of these analogues in cell and molecular biology will be presented in due course.

\section{Experimental Section}

\section{General}

Chemicals were purchased from Aldrich and Acros Chemical Corporation and used without prior purification. Solvents were reagent-grade and distilled before use: $\mathrm{CH}_{2} \mathrm{Cl}_{2}$ was distilled from $\mathrm{CaH}_{2}$ and THF was distilled from sodium wire. TLC used precoated silica gel aluminum sheets (EM SCIENCE silica gel $60 \mathrm{~F}_{254}$ ). Flash chromatography (FC) employed Whatman 230 400 mesh ASTM silica gel. NMR spectra were recorded on a Varian INOVA 400 at 400 $\mathrm{MHz}\left({ }^{1} \mathrm{H}\right), 101 \mathrm{MHz}\left({ }^{13} \mathrm{C}\right), 162 \mathrm{MHz}\left({ }^{31} \mathrm{P}\right)$ and $376 \mathrm{MHz}\left({ }^{19} \mathrm{~F}\right)$ at $25^{\circ} \mathrm{C}$. Chemical shifts are reported in ppm with TMS as internal standard $(\delta=0.00) ;{ }^{31} \mathrm{P}, 85 \% \mathrm{H}_{3} \mathrm{PO}_{4}(\delta=0.00) ;{ }^{19} \mathrm{~F}$, $\mathrm{CFCl}_{3}(\delta=0.00)$. Low- and high-resolution mass spectra were obtained on HP5971 A MSD and Finnigan MAT95 double focusing mass spectrometer (MS) instruments, respectively. Dibutyryl and dipalmitoyl PtdIns(3)P were obtained from Echelon Biosciences (Salt Lake City, UT).

\section{Methyl methylphosphonyl chloride (4)}

To $12.87 \mathrm{~g}(0.104 \mathrm{~mol})$ of dimethyl methylphosphonate in $30 \mathrm{~mL}$ of anhydrous benzene was added $21.6 \mathrm{~g}(0.104 \mathrm{~mol})$ of $\mathrm{PCl}_{5}$ at $0{ }^{\circ} \mathrm{C}$. The solution was stirred vigorously for $1 \mathrm{~h}$ at $0{ }^{\circ} \mathrm{C}$. The solvent was removed under vacuum. Vacuum distillation $\left(80^{\circ} \mathrm{C} / 22 \mathrm{mmHg}\right)$ gave $12.1 \mathrm{~g}$ (0.094 mol, $94 \%)$ of homogeneous product. ${ }^{1} \mathrm{H} \mathrm{NMR}\left(\mathrm{CDCl}_{3}\right): \delta 3.72(\mathrm{~d}, J=6.0 \mathrm{~Hz}, 2 \mathrm{H}), 3.57$ $(\mathrm{d}, J=10.5 \mathrm{~Hz}, 6 \mathrm{H}) .{ }^{13} \mathrm{C} \mathrm{NMR}\left(\mathrm{CDCl}_{3}\right): \delta 56.40(\mathrm{~s}), 54.78(\mathrm{~s}), 53.14(\mathrm{~s}), 53.07(\mathrm{~s}) .{ }^{31} \mathrm{P}$ NMR $\left(\mathrm{CDCl}_{3}\right): \delta 28.18(\mathrm{~s})$. MS (CI) $m / 2.129 .0\left(\mathrm{M}^{+}+1,8.32\right)$. HRMS (CI), $\mathrm{M}^{+}+1$, Found: 128.9872; calcd for $\mathrm{C}_{2} \mathrm{H}_{6} \mathrm{ClO}_{2} \mathrm{P}, 128.9871$.

\section{Dimethoxyphosphinylmethyl triflates (7)}

To a stirred solution of dimethoxy (hydroxymethyl)phosphonate $(30.6 \mathrm{mmol})$ and 2,6-lutidine (37.6 mmol) in anhydrous $\mathrm{CH}_{2} \mathrm{Cl}_{2}(50 \mathrm{~mL})$ at $-50{ }^{\circ} \mathrm{C}$ under $\mathrm{N}_{2}$ was added trifluoromethanesulfonic anhydride $(35.5 \mathrm{mmol})$ dropwise. The resulting mixture was allowed to warm to $0{ }^{\circ} \mathrm{C}$ over a period of $1.5 \mathrm{~h}$, whereupon the dark brown solution was diluted with ether $(300 \mathrm{~mL})$. The precipitates formed were removed by filtration. The ethereal solution was successively washed with water, $1 \mathrm{~N} \mathrm{HCl}$, and brine and then dried over $\mathrm{Na}_{2} \mathrm{SO}_{4}$. After concentration, a yellow oil was obtained, which was used in the next step without further purification.

\section{Dimethyl fluoromethylphosphonate (8)}

A solution of the triflate $7(5.08 \mathrm{~g}, 0.015 \mathrm{~mol})$ in THF $(22 \mathrm{~mL})$ was cooled to $0{ }^{\circ} \mathrm{C}$ before 20 $\mathrm{mL}(0.02 \mathrm{~mol})$ of a $1 \mathrm{M}$ solution of tetrabutylammonium fluoride in THF was added dropwise. 
The solution was stirred at $0{ }^{\circ} \mathrm{C}$ for $1 \mathrm{~h}$. Solvents were then removed and $\mathrm{CH}_{2} \mathrm{Cl}_{2}(35 \mathrm{~mL})$ was added. The organic layer was washed $\left(\mathrm{H}_{2} \mathrm{O}, 3 \times 8 \mathrm{~mL}\right)$, dried $\left(\mathrm{MgSO}_{4}\right)$ and evaporated to a crude oil. This was purified by FC, using EtOAc-hexane (1:1) as eluent, to give $\mathbf{8}$ as a pale yellow oil $(1.67 \mathrm{~g}, 67 \%) .{ }^{1} \mathrm{H}$ NMR $\left(\mathrm{CDCl}_{3}\right): \delta 4.68(\mathrm{dd}, J=46.8,4.8 \mathrm{~Hz}, 2 \mathrm{H}), 3.81(\mathrm{~d}, J=$ $10.8 \mathrm{~Hz}, 6 \mathrm{H}) .{ }^{31} \mathrm{P}$ NMR $\left(\mathrm{CDCl}_{3}\right): \delta 19.83(\mathrm{~d}, J=63.0 \mathrm{~Hz}) .{ }^{19} \mathrm{~F}$ NMR $\left(\mathrm{CDCl}_{3}\right): \delta-250.74$ (dt, $J=61.7,47.0 \mathrm{~Hz})$. MS (CI) $m / z, 143.0\left(\mathrm{M}^{+}+1,100.00\right)$. HRMS (CI), $\mathrm{M}^{+}+1$, Found: 143.0262; calcd for $\mathrm{C}_{3} \mathrm{H}_{9} \mathrm{FO}_{3} \mathrm{P}, 143.0267$.

\section{Methyl fluoromethylphosphonate chloride (9)}

Dimethyl fluoromethylphosphonate $8(0.221 \mathrm{~g}, 0.592 \mathrm{mmol})$ was dissolved in $t$-butylamine (8 $\mathrm{mL}, 76 \mathrm{mmol}$ ) and heated at reflux overnight. The reaction was concentrated and gave 0.256 $\mathrm{g}$ of product as a white salt (quantitative yield). Methyl fluoromethylphosphonate $t$-butylamine salt $(0.290 \mathrm{~g}, 0.670 \mathrm{mmol})$ was dissolved in $\mathrm{CHCl}_{3}$ and treated with cation exchange resin (Dowex 50W-X8 ( $\mathrm{H}^{+}$form) $200-400$ mesh). The Dowex ${ }^{\circledR}$ resin was removed by filtration and the filtrate was concentrated in vacuo to give $0.241 \mathrm{~g}$ (quantitative yield) of the oily phosphonate. Next, oxalyl chloride $(0.132 \mathrm{~g}, 1.04 \mathrm{mmol})$ was added dropwise to a solution of the methyl fluoromethylphosphonic acid $(0.240 \mathrm{~g}, 0.668 \mathrm{mmol})$ and $\mathrm{DMF}(2.5 \mu \mathrm{L}, 0.033$ mmol) dissolved in $\mathrm{CH}_{2} \mathrm{Cl}_{2}$ at $0{ }^{\circ} \mathrm{C}$. The solution was stirred at $0{ }^{\circ} \mathrm{C}$ for $20 \mathrm{~min}$ and then warmed to $\mathrm{rt}$ and stirred for $1.5 \mathrm{~h}$. The reaction was concentrated, dissolved in toluene $(2 \mathrm{~mL})$, and then re-concentrated in vacuo to remove the volatile reagents. This gave phosphonochloridate 9 as a yellow oil, which was then used immediately for reaction with the 3-hydroxy-containing protected inositol derivatives. ${ }^{1} \mathrm{H}$ NMR $\left(\mathrm{CDCl}_{3}\right): \delta 4.62(\mathrm{dd}, J=46.8,4.4 \mathrm{~Hz}, 2 \mathrm{H}), 3.74(\mathrm{~d}$, $J=11.2 \mathrm{~Hz}, 3 \mathrm{H}) .{ }^{13} \mathrm{C} \mathrm{NMR}\left(\mathrm{CDCl}_{3}\right): \delta 75.72(\mathrm{dd}, J=180.2,168.7 \mathrm{~Hz}), 53.14(\mathrm{~d}, J=6.1$ $\mathrm{Hz}) .{ }^{31} \mathrm{P} \mathrm{NMR}\left(\mathrm{CDCl}_{3}\right): \delta 19.80(\mathrm{~d}, J=63.0 \mathrm{~Hz}) .{ }^{19} \mathrm{~F} \mathrm{NMR}\left(\mathrm{CDCl}_{3}\right): \delta-250.98(\mathrm{dt}, J=62.8$, $47.0 \mathrm{~Hz})$. MS (CI) $\mathrm{m} / \mathrm{z} 147.0\left(\mathrm{M}^{+}+1,100.00\right)$. HRMS (CI), $\mathrm{M}^{+}+1$, Found: 146.9759 Calcd for $\mathrm{C}_{2} \mathrm{H}_{6} \mathrm{ClFO}_{2} \mathrm{P}, 146.9778$.

\section{D-1-O-(tert-Butyldiphenylsilyl)-3-(methyl methylphosphonate)-2,4,5,6-O-tetrakis (methoxymethylene)-myo-inositol (11a)}

$t$-BuOK (18 mg, $0.163 \mathrm{mmol}, 1.4$ equiv) was added to a stirred solution of ( $69 \mathrm{mg}, 0.116 \mathrm{mmol}$ ) 10 and methyl methylphosphonate chloride (18 mg, $0.139 \mathrm{mmol}, 1.2 \mathrm{eq}$.) in $\mathrm{CH}_{2} \mathrm{Cl}_{2}(1 \mathrm{~mL})$ at $0^{\circ} \mathrm{C}$, then stirred $2 \mathrm{~h}$ at $\mathrm{rt}$ and the reaction was complete. A saturated aq solution of $\mathrm{NH}_{4} \mathrm{Cl}$ $(1 \mathrm{~mL})$ was added, stirred $10 \mathrm{~min}$, the aqueous phase was extracted with $\mathrm{CH}_{2} \mathrm{Cl}_{2}(3 \times 5 \mathrm{~mL})$, the organic solution was dried with anhydrous $\mathrm{Na}_{2} \mathrm{SO}_{4}$, and the solvent was evaporated under reduced pressure. The crude product was purified by chromatography ( $n$-hexane-acetone, $2: 1$, v:v) to afford a colorless liquid ( $37 \mathrm{mg}, 0.054 \mathrm{mmol}, 46 \%) .{ }^{1} \mathrm{H}$ NMR $\left(\mathrm{CDCl}_{3}\right): \delta 7.72-7.67$ $(\mathrm{m}, 4 \mathrm{H}), 7.41-7.36(\mathrm{~m}, 6 \mathrm{H}), 4.98(\mathrm{~d}, J=4.4 \mathrm{~Hz}, 1 \mathrm{H}), 4.91(\mathrm{~d}, J=4.4 \mathrm{~Hz}, 1 \mathrm{H}), 4.79(\mathrm{~d}, J=4.4$ $\mathrm{Hz}, 1 \mathrm{H}), 4.75(\mathrm{~m}, 3 \mathrm{H}), 4.57(\mathrm{~d}, J=4.8 \mathrm{~Hz}, 1 \mathrm{H}), 4.26(\mathrm{~d}, J=4.8 \mathrm{~Hz}, 1 \mathrm{H}), 3.92-3.85(\mathrm{~m}, 4 \mathrm{H})$, $3.86(\mathrm{~d}, J=6.0 \mathrm{~Hz}, 3 \mathrm{H}), 3.42-3.32(\mathrm{~m}, 12 \mathrm{H}), 3.20(\mathrm{~d}, J=23.0 \mathrm{~Hz}, 2 \mathrm{H}), 1.34(\mathrm{~d}, J=17.6 \mathrm{~Hz}$, $3 \mathrm{H}), 1.06(\mathrm{~s}, 9 \mathrm{H}) .{ }^{13} \mathrm{C} \mathrm{NMR}\left(\mathrm{CDCl}_{3}\right): \delta 135.93(\mathrm{~s}), 135.81(\mathrm{~s}), 133.80(\mathrm{~s}), 133.77(\mathrm{~s}), 132.51$ (s), $132.48(\mathrm{~s}), 129.95$ (s), $129.86(\mathrm{~s}), 129.80$ (s), 128.01 (s), 127.89 (s), 127.71 (s), 127.69 (s), $98.93(\mathrm{~s}), 98.35$ (s), $98.30(\mathrm{~s}), 98.22(\mathrm{~s}), 97.46(\mathrm{~d}, J=14.58 \mathrm{~Hz}), 82.04(\mathrm{~d}, J=8.45 \mathrm{~Hz}), 81.28$ (d, $J=5.43 \mathrm{~Hz}), 78.88(\mathrm{~d}, J=34.49 \mathrm{~Hz}), 74.84$ (s), 70.49 (s), 56.05 (dd, $J=62.05,24.54 \mathrm{~Hz}$ ), 27.07 (s). ${ }^{31} \mathrm{P} \mathrm{NMR}\left(\mathrm{CDCl}_{3}\right): \delta 33.89$ (s), 33.04 (s). MS (CI) $\mathrm{m} / z$ 687.1 $\left(\mathrm{M}^{+}+1,79.67\right), 655.1$ $\left(\mathrm{M}^{+}-\mathrm{OCH}_{3}, 100.00\right)$. HRMS (CI), $\mathrm{M}^{+}+1$, Found: 687.2962; calcd for $\mathrm{C}_{32} \mathrm{H}_{52} \mathrm{O}_{12} \mathrm{PSi}$, 687.2966.

\section{D-3-(Methyl methylphosphonate)-2,4,5,6-O-tetrakis(methoxymethylene)-myo-inositol (12a)}

A solution of (24 mg, $0.035 \mathrm{mmol})$ in THF $(1 \mathrm{~mL})$ was treated with tetrabutylammoniumfluoride trihydrate $(16 \mathrm{mg}, 0.049 \mathrm{mmol})$ at $\mathrm{rt}$. After stirring for $18 \mathrm{~h}$, the reaction was complete (monitored by TLC). The solvent was evaporated under reduced 
pressure and the crude product was purified by passage through a short silica gel column ( $n$ hexane-acetone, 3:1, v:v) to afford $12 \mathrm{mg}$ of a colorless liquid $(0.027 \mathrm{mmol}, 77 \%) .{ }^{1} \mathrm{H}$ NMR $\left(\mathrm{CDCl}_{3}\right): \delta$ 4.79-4.64 (m, 8H), $4.17(\mathrm{t}, J=10.4 \mathrm{~Hz}, 1 \mathrm{H}), 4.10(\mathrm{~d}, J=20.4 \mathrm{~Hz}, 1 \mathrm{H}), 3.98(\mathrm{dd}$, $J=11.6,4.4 \mathrm{~Hz}, 1 \mathrm{H}), 3.89(\mathrm{dd}, J=21.2,9.6 \mathrm{~Hz}, 1 \mathrm{H}), 3.69(\mathrm{dd}, J=20.0,9.2 \mathrm{~Hz}, 1 \mathrm{H}), 3.58(\mathrm{td}$, $J=9.2,1.2 \mathrm{~Hz}, 1 \mathrm{H}), 3.42(\mathrm{~m}, 1 \mathrm{H}), 3.41-3.34(\mathrm{~m}, 15 \mathrm{H}), 1.46(\mathrm{dd}, J=18.0,3.6 \mathrm{~Hz}, 3 \mathrm{H}) .{ }^{13} \mathrm{C}$ NMR $\left(\mathrm{CDCl}_{3}\right): \delta 98.52(\mathrm{~s}), 98.35(\mathrm{~s}), 98.31(\mathrm{~s}), 98.26(\mathrm{~s}), 98.17(\mathrm{~s}), 98.11(\mathrm{~s}), 97.97(\mathrm{~s}), 82.93$ (s), $79.11(\mathrm{~d}, J=16.09 \mathrm{~Hz}), 78.41(\mathrm{~d}, J=6.94 \mathrm{~Hz}), 76.50(\mathrm{~d}, J=6.13 \mathrm{~Hz}), 74.82(\mathrm{dd}, J=29.06$, $6.84 \mathrm{~Hz}), 70.40(\mathrm{~d}, J=5.33 \mathrm{~Hz}), 52.03(\mathrm{dd}, J=40.63,6.13 \mathrm{~Hz}), 10.97(\mathrm{dd}, J=146.52,23.73$ $\mathrm{Hz}) .{ }^{31} \mathrm{P}$ NMR $\left(\mathrm{CDCl}_{3}\right): \delta 34.60$ (s), 33.36 (s). MS (CI) $\mathrm{m} / z$ 449.1 $\left(\mathrm{M}^{+}+1,100.00\right)$. HRMS (CI), $\mathrm{M}^{+}+1$, Found: 449.1779; calcd for $\mathrm{C}_{16} \mathrm{H}_{34} \mathrm{O}_{12} \mathrm{P}, 449.1788$.

\section{D-O-(1,2-Di-O-oleoyl-sn-(2S)-glycerol-3-O-methylphospho)-3-(methyl methylphosphonate)-2,4,5,6-0-tetrakis(methoxymethylene)-myo-inositol (13a)}

$N, N$-Diisopropyl- $O$-methyl- $O$-(di-(2S)-oleoyl-sn-glycerol)phosphonamidite $(0.187 \mathrm{~g}, 0.135$ mmol) was added under an argon atmosphere to a solution of 12a $(110 \mathrm{mg}, 0.089 \mathrm{mmol})$ and $1 H$-tetrazole (26 mg, $0.374 \mathrm{mmol}$ ) in $4 \mathrm{~mL}$ dry $\mathrm{CH}_{2} \mathrm{Cl}_{2} / \mathrm{THF}(1 / 1, \mathrm{v} / \mathrm{v})$. After stirring for 20 $\mathrm{h}$ at $\mathrm{rt}$, oxidation was performed with $\left(n-\mathrm{C}_{4} \mathrm{H}_{9}\right)_{4} \mathrm{NIO}_{4}(78 \mathrm{mg}, 0.180 \mathrm{mmol})$ at $-20^{\circ} \mathrm{C}$ for $1 \mathrm{~h}$. The reaction mixture was warmed to rt for an additional $30 \mathrm{~min}$, and after aqueous work-up, the crude product was purified by FC on silica gel ( $n$-hexane/acetone, 3/1, v/v) to give $77 \mathrm{mg}$ of a homogeneous colorless oil $(0.068 \mathrm{mmol}, 76 \%) .{ }^{1} \mathrm{H} \mathrm{NMR}\left(\mathrm{CDCl}_{3}\right): \delta 5.32(\mathrm{~m}, 2 \mathrm{H}), 5.21$ $(\mathrm{m}, 1 \mathrm{H}), 4.84-4.71(\mathrm{~m}, 8 \mathrm{H}), 4.32-4.09(\mathrm{~m}, 8 \mathrm{H}), 3.96-3.89(\mathrm{~m}, 2 \mathrm{H}), 3.77-3.72(\mathrm{~m}, 6 \mathrm{H}), 3.41-3.33$ (m, 12H), $2.29(\mathrm{~m}, 4 \mathrm{H}), 1.96(\mathrm{~m}, 8 \mathrm{H}), 1.55(\mathrm{~m}, 4 \mathrm{H}), 1.52(\mathrm{dd}, J=17.6,6.8 \mathrm{~Hz}, 3 \mathrm{H}), 1.21(\mathrm{~m}$, 42H), $0.84(\mathrm{t}, J=7.2 \mathrm{~Hz}, 6 \mathrm{H}) .{ }^{13} \mathrm{C} \mathrm{NMR}\left(\mathrm{CDCl}_{3}\right): \delta 173.15(\mathrm{~s}), 172.73(\mathrm{~s}), 129.91(\mathrm{~s}), 129.66$ (s), 98.91 (s), 98.54 (s), 98.45 (s), 98.37 (s), 98.03 (s), 97.85 (s), 79.13 (d, J=13.78 Hz), 74.24 (dd, $J=31.48,6.13 \mathrm{~Hz}), 69.37(\mathrm{~s}), 65.80(\mathrm{~s}), 65.52(\mathrm{~s}), 61.61(\mathrm{~s}), 56.78(\mathrm{~s}), 56.65(\mathrm{~s}), 56.56$ (s), $56.51(\mathrm{~s}), 55.76(\mathrm{~s}), 54.81(\mathrm{~s}), 53.75(\mathrm{~s}), 52.18(\mathrm{dd}, J=35.30,6.13 \mathrm{~Hz}), 34.08(\mathrm{~s}), 33.96$ (s), $31.88(\mathrm{~s}), 29.65(\mathrm{~s}), 29.63(\mathrm{~s}), 29.61(\mathrm{~s}), 29.45(\mathrm{~s}), 29.31(\mathrm{~s}), 29.25(\mathrm{~s}), 29.22(\mathrm{~s}), 29.09(\mathrm{~s})$, $29.06(\mathrm{~s}), 24.78(\mathrm{~s}), 22.64(\mathrm{~s}), 14.07(\mathrm{~s}), 11.03$ (dd, $J=148.83,12.27 \mathrm{~Hz}) .{ }^{31} \mathrm{P}$ NMR $\left(\mathrm{CDCl}_{3}\right): \delta 34.60(\mathrm{~s}), 33.49(\mathrm{~s}), 0.74(\mathrm{~s}), 0.52(\mathrm{~d}, J=7.61 \mathrm{~Hz}) . \mathrm{MS}(\mathrm{CI}) \mathrm{m} / \mathrm{z} 1145.7\left(\mathrm{M}^{+}+1\right.$, 100.00). HRMS (CI), $\mathrm{M}^{+}+1$, Found: 1145.6897 ; calcd for $\mathrm{C}_{56} \mathrm{H}_{107} \mathrm{O}_{19} \mathrm{P}_{2}, 1145.6882$.

\section{D-O-(1,2-di-O-oleoyl-sn-(2S)-glycerol-3-phospho)-3-(methylphosphonate)-myo-inositol (15a)}

The phosphate 13a (22 $\mathrm{mg}, 0.019 \mathrm{mmol})$ in $5 \mathrm{~mL}$ flask was dried in vacuo, and then anhydrous TMSBr $(0.2 \mathrm{~mL})$ and $\mathrm{CH}_{2} \mathrm{Cl}_{2}(0.2 \mathrm{~mL})$ were added into the flask. The solution was stirred at rt for $30 \mathrm{~min}$. TMSBr and volatile products were evaporated under high vacuum during $6 \mathrm{~h}$. The residue was dissolved in $\mathrm{MeOH}-\mathrm{H}_{2} \mathrm{O}(95: 5,1.0 \mathrm{~mL})$ and stirred for $30 \mathrm{~min}$ at rt. The solution was thoroughly concentrated for an additional $3 \mathrm{~h}$ under high vacuum. Ethanethiol (1 $\mathrm{mL}$ ) was added, the solution was kept at $\mathrm{rt}$ for $1 \mathrm{~h}$, and then concentrated to yield the crude product. Chromatography on silica gel $\left(\mathrm{CHCl}_{3}-\mathrm{CH}_{3} \mathrm{OH}-\mathrm{NH}_{4} \mathrm{OH}(2.0 \mathrm{M}), 65: 25: 3\right.$, v:v:v) provided $16 \mathrm{mg}$ of pure product $15 \mathbf{a}(0.017 \mathrm{mmol}, 89 \%) .{ }^{1} \mathrm{H} \mathrm{NMR}\left(\mathrm{CDCl}_{3} / \mathrm{CD}_{3} \mathrm{OD}, 3 / 2, \mathrm{v} / \mathrm{v}\right)$ : $\delta 5.32(\mathrm{~m}, 2 \mathrm{H}), 5.21(\mathrm{~m}, 1 \mathrm{H}), 3.93(\mathrm{dd}, J=12.0,3.6 \mathrm{~Hz}, 1 \mathrm{H}), 3.82(\mathrm{~m}, 2 \mathrm{H}), 3.73-3.60(\mathrm{~m}, 5 \mathrm{H})$, $3.30(\mathrm{~m}, 2 \mathrm{H}), 2.33(\mathrm{~m}, 4 \mathrm{H}), 1.96(\mathrm{~m}, 8 \mathrm{H}), 1.55(\mathrm{~m}, 4 \mathrm{H}), 1.52(\mathrm{dd}, J=17.6,6.8 \mathrm{~Hz}, 3 \mathrm{H}), 1.21$ $(\mathrm{m}, 42 \mathrm{H}), 0.84(\mathrm{t}, J=7.2 \mathrm{~Hz}, 6 \mathrm{H}) .{ }^{13} \mathrm{C} \mathrm{NMR}\left(\mathrm{CDCl}_{3} / \mathrm{CD}_{3} \mathrm{OD}, 3 / 2, \mathrm{v} / \mathrm{v}\right): \delta 173.28(\mathrm{~s}), 172.89$ (s), $129.25(\mathrm{~s}), 128.98(\mathrm{~s}), 97.13(\mathrm{~s}), 73.70(\mathrm{~s}), 70.87(\mathrm{~s}), 70.46(\mathrm{~s}), 69.98(\mathrm{~s}), 69.33(\mathrm{~s}), 64.39$ (s), $61.60(\mathrm{~s}), 54.88(\mathrm{~s}), 42.53(\mathrm{~s}), 42.46(\mathrm{~s}), 33.30(\mathrm{~s}), 31.24(\mathrm{~s}), 29.26(\mathrm{~s}), 29.06(\mathrm{~s}), 28.83(\mathrm{~s})$, $28.64(\mathrm{~s}), 28.60(\mathrm{~s}), 28.56(\mathrm{~s}), 28.53(\mathrm{~s}), 28.45(\mathrm{~s}), 28.43(\mathrm{~s}), 28.39(\mathrm{~s}), 26.46(\mathrm{~s}), 24.17(\mathrm{~s})$, $21.96(\mathrm{~s}), 13.08(\mathrm{~s}), 10.62(\mathrm{~d}, J=140.80 \mathrm{~Hz}) .{ }^{31} \mathrm{P} \mathrm{NMR}\left(\mathrm{CDCl}_{3} / \mathrm{CD}_{3} \mathrm{OD}, 3 / 2, \mathrm{v} / \mathrm{v}\right): \delta 32.56$ (s), 32.40 (s), -0.51 (s). MS (ESI) $\mathrm{m} / z, 963.53\left(\mathrm{M}^{+}+\mathrm{Na}, \mathrm{C}_{46} \mathrm{H}_{86} \mathrm{NaO}_{15} \mathrm{P}_{2}, 100.0\right)$. HRMS (MALDI), $\mathrm{M}^{+}+\mathrm{Na}$, Found: 963.5312; calcd for $\mathrm{C}_{46} \mathrm{H}_{86} \mathrm{NaO}_{15} \mathrm{P}_{2}, 963.5340$. 
1D-O-(1,2-Di-O-palmitoyl-sn-(2S)-glycerol-3-O-methylphospho)-3-(methyl methylphosphonate)-2,4,5,6-O-tetrakis(methoxymethylene)-myo-inositol (13b)

$N, N$-diisopropyl- $O$-methyl- $O$-(di-(2S)-palmitoyl-sn-glycerol)phosphonamidite (91 mg, 0.125 mmol) was added under an argon atmosphere to a solution of $12 \mathrm{a}(37 \mathrm{mg}, 0.083 \mathrm{mmol})$ and $1 \mathrm{H}$-tetrazole $(25 \mathrm{mg}, 0.349 \mathrm{mmol})$ in $4 \mathrm{~mL}$ of dry $\mathrm{CH}_{2} \mathrm{Cl}_{2}$-THF (1:1, v:v). After stirring for $20 \mathrm{~h}$ at rt, oxidation was performed with $\left(n-\mathrm{C}_{4} \mathrm{H}_{9}\right)_{4} \mathrm{NIO}_{4}(69 \mathrm{mg}, 0.160 \mathrm{mmol})$ at $-20{ }^{\circ} \mathrm{C}$ for $1 \mathrm{~h}$. The reaction mixture was warmed to $\mathrm{rt}$ for an additional $30 \mathrm{~min}$, and after aqueous workup, the crude product was chromatographed on silica gel ( $n$-hexane-acetone, $3: 1, \mathrm{v}: \mathrm{v})$ to give $67 \mathrm{mg}$ pure $13 \mathrm{~b}$ as a colorless oil $(0.061 \mathrm{mmol}, 73 \%) .{ }^{1} \mathrm{H} \mathrm{NMR}\left(\mathrm{CDCl}_{3}\right): \delta 5.21(\mathrm{~m}, 1 \mathrm{H})$, 4.84-4.71 (m, 8H), 4.34-4.07 (m, 8H), 3.96-3.89 (m, 2H), 3.77-3.72 (m, 6H), 3.41-3.33 (m, $12 \mathrm{H}), 2.29(\mathrm{~m}, 4 \mathrm{H}), 1.55(\mathrm{~m}, 4 \mathrm{H}), 1.52(\mathrm{dd}, J=17.6,6.8 \mathrm{~Hz}, 3 \mathrm{H}), 1.21(\mathrm{~m}, 48 \mathrm{H}), 0.84(\mathrm{t}, J=$ $7.2 \mathrm{~Hz}, 6 \mathrm{H}) .{ }^{13} \mathrm{C} \mathrm{NMR}\left(\mathrm{CDCl}_{3}\right): \delta 173.19(\mathrm{~s}), 172.80(\mathrm{~s}), 98.90(\mathrm{~s}), 98.53(\mathrm{~s}), 98.43(\mathrm{~s}), 98.35$ (s), $98.03(\mathrm{~s}), 97.83(\mathrm{~s}), 79.13(\mathrm{~d}, J=13.78 \mathrm{~Hz}), 77.21(\mathrm{~s}), 76.90(\mathrm{~s}), 76.35(\mathrm{~s}), 74.24(\mathrm{dd}, J=$ 31.48, $6.13 \mathrm{~Hz}), 69.44(\mathrm{~s}), 69.35(\mathrm{~s}), 65.75(\mathrm{~s}), 65.57$ (s), $61.60(\mathrm{~s}), 56.77$ (s), $56.64(\mathrm{~s}), 56.55$ (s), $56.50(\mathrm{~s}), 55.75(\mathrm{~s}), 53.75(\mathrm{~s}), 52.18(\mathrm{dd}, J=35.30,6.13 \mathrm{~Hz}), 34.08(\mathrm{~s}), 33.96(\mathrm{~s}), 31.88$ $(\mathrm{s}), 29.65(\mathrm{~s}), 29.63(\mathrm{~s}), 29.61(\mathrm{~s}), 29.45(\mathrm{~s}), 29.31(\mathrm{~s}), 29.25(\mathrm{~s}), 29.22(\mathrm{~s}), 29.09(\mathrm{~s}), 29.06(\mathrm{~s})$, $24.78(\mathrm{~s}), 22.64(\mathrm{~s}), 14.07(\mathrm{~s}), 11.03(\mathrm{dd}, J=148.83,12.27 \mathrm{~Hz}) .{ }^{31} \mathrm{P} \mathrm{NMR}\left(\mathrm{CDCl}_{3}\right): \delta 34.60$ $(\mathrm{d}, J=8.74 \mathrm{~Hz}), 33.51(\mathrm{~d}, J=6.64 \mathrm{~Hz}), 0.74(\mathrm{~s}), 0.53(\mathrm{~d}, J=8.74 \mathrm{~Hz})$. MS (CI) $\mathrm{m} / z .1093 .7$ $\left(\mathrm{M}^{+}+1,4.58\right)$. HRMS (CI), $\mathrm{M}^{+}+1$, Found: 1093.6583 ; calcd for $\mathrm{C}_{52} \mathrm{H}_{103} \mathrm{O}_{19} \mathrm{P}_{2}, 1093.6569$.

\section{D-O-(1,2-Di-O-palmitoyl-sn-(2S)-glycerol-3-phospho)-3-(methylphosphonate)-myo-inositol (15b)}

The phosphate 13b (29 mg, $0.027 \mathrm{mmol})$ in $5 \mathrm{~mL}$ flask was thoroughly dried in vacuo, and then anhydrous TMSBr $(0.2 \mathrm{~mL})$ and $\mathrm{CH}_{2} \mathrm{Cl}_{2}(0.2 \mathrm{~mL})$ were added. The solution was stirred at $\mathrm{rt}$ for $30 \mathrm{~min}$. TMSBr and volatile products were evaporated under high vacuum during $6 \mathrm{~h}$. The residue was dissolved in $\mathrm{MeOH}-\mathrm{H}_{2} \mathrm{O}(95: 5,1.0 \mathrm{~mL})$ and stirred for $30 \mathrm{~min}$ at rt. The solution was thoroughly concentrated for an additional $3 \mathrm{~h}$ under high vacuum. Ethanethiol (1 $\mathrm{mL}$ ) was added, the solution was kept at $\mathrm{rt}$ for $1 \mathrm{~h}$, and then concentrated to yield the crude product. Chromatography on silica gel $\left(\mathrm{CHCl}_{3}-\mathrm{CH}_{3} \mathrm{OH}-\mathrm{NH}_{4} \mathrm{OH}(2.0 \mathrm{M}), 65: 25: 3\right.$, v:v:v) provided $22 \mathrm{mg}$ of pure product $15 \mathbf{b}(0.025 \mathrm{mmol}, 92 \%) .{ }^{1} \mathrm{H}$ NMR $\left(\mathrm{CDCl}_{3}-\mathrm{CD}_{3} \mathrm{OD}, 3: 2, \mathrm{v}: \mathrm{v}\right)$ : $\delta 5.27(\mathrm{~m}, 1 \mathrm{H}), 3.93(\mathrm{dd}, J=12.0,3.6 \mathrm{~Hz}, 1 \mathrm{H}), 3.82(\mathrm{~m}, 2 \mathrm{H}), 3.73-3.60(\mathrm{~m}, 6 \mathrm{H}), 3.30(\mathrm{~m}, 2 \mathrm{H})$, $2.33(\mathrm{~m}, 4 \mathrm{H}), 1.62(\mathrm{~m}, 4 \mathrm{H}), 1.56(\mathrm{dd}, J=17.6,6.8 \mathrm{~Hz}, 3 \mathrm{H}), 1.27(\mathrm{~m}, 48 \mathrm{H}), 0.84(\mathrm{t}, J=7.2 \mathrm{~Hz}$, 6H). ${ }^{13} \mathrm{C} \mathrm{NMR}\left(\mathrm{CDCl}_{3} / \mathrm{CD}_{3} \mathrm{OD}, 3 / 2\right.$, v/v): $\delta 173.17(\mathrm{~s}), 172.75(\mathrm{~s}), 98.20(\mathrm{~s}), 73.80(\mathrm{~s}), 70.97$ $(\mathrm{s}), 70.55(\mathrm{~s}), 70.02(\mathrm{~s}), 69.74(\mathrm{~s}), 64.52(\mathrm{~s}), 61.81(\mathrm{~s}), 54.97(\mathrm{~s}), 33.45(\mathrm{~s}), 33.42(\mathrm{~s}), 31.36(\mathrm{~s})$, $29.32(\mathrm{~s}), 29.12(\mathrm{~s}), 28.85(\mathrm{~s}), 28.64(\mathrm{~s}), 28.70(\mathrm{~s}), 14.01(\mathrm{~s}), 10.58(\mathrm{~d}, J=138.20 \mathrm{~Hz}) .{ }^{31} \mathrm{P}$ $\mathrm{NMR}\left(\mathrm{CDCl}_{3}-\mathrm{CD}_{3} \mathrm{OD}, 3: 2, \mathrm{v}: \mathrm{v}\right): \delta 32.45(\mathrm{~s}), 32.30(\mathrm{~s}), 0.74(\mathrm{~s}),-0.55$ (s). MS (ESI) $\mathrm{m} / z 911.50$ $\left(\mathrm{M}^{+}+\mathrm{Na}, \mathrm{C}_{42} \mathrm{H}_{82} \mathrm{NaO}_{15} \mathrm{P}_{2}, 100.00\right)$. HRMS (MALDI), $\mathrm{M}^{+}+\mathrm{Na}$, Found: 911.5045 ; calcd for $\mathrm{C}_{42} \mathrm{H}_{82} \mathrm{NaO}_{15} \mathrm{P}_{2}, 911.5027$.

\section{D-O-(1,2-di-O-butanoyl-sn-(2S)-glycerol-3-O-methylphospho)-3-(methyl methylphosphonate)-2,4,5,6-O-tetrakis(methoxymethylene)-myo-inositol (13c)}

To a solution of alcohol 12a $(17 \mathrm{mg}, 0.038 \mathrm{mmol})$ in dry THF $(0.5 \mathrm{~mL})$, was added $N, N$ diisopropyl- $O$-(methyl)- $O$-di- $O$-butanoyl-sn-(2S)-glycerol)phosphonamidite $(25 \mathrm{mg}, 24 \mu \mathrm{L}$, $0.125 \mathrm{mmol}$ ) and $1 \mathrm{H}$-tetrazole ( $26 \mathrm{mg}, 0.374 \mathrm{mmol}$ ). The mixture was stirred at $\mathrm{rt}$ for 16 hour. Then oxidation was performed with $\left(n-\mathrm{C}_{4} \mathrm{H}_{9}\right)_{4} \mathrm{NIO}_{4}(76 \mathrm{mg}, 0.174 \mathrm{mmol})$ at $-20{ }^{\circ} \mathrm{C}$ for $1 \mathrm{~h}$. The reaction mixture was warmed-up to rt for additional $30 \mathrm{~min}$. The solution was diluted with methylene chloride $(20 \mathrm{~mL})$ and washed with $10 \%$ sodium bisulfite. The organic layer was concentrated and the residue was chromatographed on silica gel ( $n$-hexane-acetone, $1: 1, \mathrm{v}: \mathrm{v})$ to give $25 \mathrm{mg}$ of pure $13 \mathrm{c}$ as colorless oil $(0.033 \mathrm{mmol}, 87 \%) .{ }^{1} \mathrm{H}$ NMR $\left(\mathrm{CDCl}_{3}\right): \delta 5.23(\mathrm{~m}$, $1 \mathrm{H})$, 4.84-4.74 (m, 8H), 4.34-4.07 (m, 8H), 3.96-3.89 (m, 2H), 3.77-3.72 (m, 6H), 3.41-3.33 (m, 12H), $2.31(\mathrm{~m}, 4 \mathrm{H}), 1.62(\mathrm{~m}, 4 \mathrm{H}), 1.52(\mathrm{dd}, J=17.6,6.8 \mathrm{~Hz}, 3 \mathrm{H}), 0.93(\mathrm{t}, J=7.2 \mathrm{~Hz}, 3 \mathrm{H})$, 
$0.90(\mathrm{t}, J=7.2 \mathrm{~Hz}, 3 \mathrm{H}),{ }^{13} \mathrm{C} \mathrm{NMR}\left(\mathrm{CDCl}_{3}\right): \delta 173.03(\mathrm{~s}), 172.90(\mathrm{~s}), 98.90(\mathrm{~s}), 98.45(\mathrm{~s}), 97.98$ $(\mathrm{s}), 97.85(\mathrm{~s}), 98.03(\mathrm{~s}), 79.20(\mathrm{~m}), 74.28(\mathrm{~d}, J=31.48 \mathrm{~Hz}), 69.36(\mathrm{~s}), 65.65(\mathrm{~d}, J=23.03 \mathrm{~Hz})$, 61.57 (s), 56.79 (s), 56.57 (s), $55.78(\mathrm{~s}), 54.59(\mathrm{~s}), 52.20(\mathrm{dd}, J=35.30,6.13 \mathrm{~Hz}), 35.93(\mathrm{~s})$, $35.83(\mathrm{~s}), 18.26(\mathrm{~s}), 13.57(\mathrm{~s}), 11.03(\mathrm{dd}, J=148.83,12.27 \mathrm{~Hz}) .{ }^{31} \mathrm{P} \mathrm{NMR}\left(\mathrm{CDCl}_{3}\right): \delta 34.65$ (s), $33.54(\mathrm{~s}), 0.75(\mathrm{~s}), 0.52(\mathrm{~d}, J=7.61 \mathrm{~Hz})$. MS (ESI) m/z $757.41\left(\mathrm{M}^{+}+1,100.00\right)$. HRMS (MALDI), $\mathrm{M}^{+}+\mathrm{Na}$, Found: 779.2627; calcd for $\mathrm{C}_{28} \mathrm{H}_{54} \mathrm{NaO}_{19} \mathrm{P}_{2}, 779.2632$.

\section{D-O-(1,2-Di-O-butanoyl-sn-(2S)-glycerol-3-phospho)-3-(methylphosphonate)-myo-inositol (15c)}

The phosphate 13c (12 mg, $0.016 \mathrm{mmol}$ ) was dried and reacted with TMSBr and then hydrolyzed in aqueous $\mathrm{MeOH}$ as described above for 15a. Ethanethiol $(1 \mathrm{~mL})$ was added, the solution was kept at $\mathrm{rt}$ for $1 \mathrm{~h}$, and then concentrated to yield the crude product.

Chromatography on silica gel $\left(\mathrm{CHCl}_{3}-\mathrm{CH}_{3} \mathrm{OH}-\mathrm{NH}_{4} \mathrm{OH}(2.0 \mathrm{M}), 65: 25: 3\right.$, v:v:v) provided 8 $\mathrm{mg}$ of pure product $15 \mathrm{c}(0.016 \mathrm{mmol}, 94 \%) .{ }^{1} \mathrm{H}$ NMR $\left(\mathrm{CDCl}_{3}-\mathrm{CD}_{3} \mathrm{OD}, 3: 2, \mathrm{v}: \mathrm{v}\right): \delta 5.27(\mathrm{~m}$, $1 \mathrm{H}), 4.74(\mathrm{~s}, 1 \mathrm{H}), 4.36(\mathrm{dd}, J=12.0,3.2 \mathrm{~Hz}, 1 \mathrm{H}), 4.28(\mathrm{~m}, 1 \mathrm{H}), 4.18-4.06(\mathrm{~m}, 5 \mathrm{H}), 3.78(\mathrm{~m}$, $2 \mathrm{H}), 3.23(\mathrm{t}, J=9.2 \mathrm{~Hz}, 1 \mathrm{H}), 2.28(\mathrm{~m}, 4 \mathrm{H}), 1.58(\mathrm{~m}, 7 \mathrm{H}), 0.99(\mathrm{~m}, 6 \mathrm{H}) .{ }^{13} \mathrm{C} \mathrm{NMR}\left(\mathrm{CDCl}_{3^{-}}\right.$ $\left.\mathrm{CD}_{3} \mathrm{OD}, 3: 2, \mathrm{v}: \mathrm{v}\right): \delta 174.32(\mathrm{~s}), 173.94(\mathrm{~s}), 98.25(\mathrm{~s}), 78.74(\mathrm{~m}), 78.36(\mathrm{~m}), 76.19(\mathrm{~m}), 74.75$ $(\mathrm{s}), 71.99(\mathrm{~s}), 71.57(\mathrm{~s}), 71.08(\mathrm{~s}), 70.32(\mathrm{~s}), 65.56(\mathrm{~s}), 62.60(\mathrm{~s}), 56.07(\mathrm{~s}), 36.42(\mathrm{~s}), 36.29(\mathrm{~s})$, $18.72(\mathrm{~s}), 13.73(\mathrm{~d}, J=3.84 \mathrm{~Hz}) .{ }^{31} \mathrm{P} \mathrm{NMR}\left(\mathrm{CDCl}_{3}-\mathrm{CD}_{3} \mathrm{OD}, 3: 2, \mathrm{v}: \mathrm{v}\right): \delta 36.57(\mathrm{~s}), 36.42(\mathrm{~s})$, 3.47 (s), 3.31 (s). MS (ESI) m/z $575.13\left(\mathrm{M}^{+}+\mathrm{Na}, \mathrm{C}_{18} \mathrm{H}_{34} \mathrm{NaO}_{15} \mathrm{P}_{2}\right.$ ). HRMS (MALDI), $\mathrm{M}^{+}+\mathrm{Na}$, Found: 575.1296; calcd for $\mathrm{C}_{18} \mathrm{H}_{34} \mathrm{NaO}_{15} \mathrm{P}_{2}, 575.1271$.

\section{D-1-O-(tert-Butyldiphenylsilyl)-3-(methyl fluoromethylphosphonate)-2,4,5,6-O-tetrakis (methoxymethylene)-myo-inositol (11b)}

$t$-BuOK (230 mg, $2.31 \mathrm{mmol}, 1.4 \mathrm{eq}$.) was added to a stirred solution of $980 \mathrm{mg}(1.65 \mathrm{mmol})$ of 10 and methyl fluoromethylphosphonate chloride (1.99 mmol, 1.2 eq.) in $\mathrm{CH}_{2} \mathrm{Cl}_{2}(10 \mathrm{~mL})$ at $0^{\circ} \mathrm{C}$; stirring was continued for $2 \mathrm{~h}$ at $\mathrm{rt}$ to complete the reaction. A saturated aqueous solution of $\mathrm{NH}_{4} \mathrm{Cl}(1 \mathrm{~mL})$ was added, stirred $10 \mathrm{~min}$, and the aqueous phase was extracted with $\mathrm{CH}_{2} \mathrm{Cl}_{2}(3 \times 5 \mathrm{~mL})$. The combined organic phases were dried with anhydrous $\mathrm{Na}_{2} \mathrm{SO}_{4}$ and the solvent was removed in vacuo. The crude product was purified by chromatography (n-hexaneacetone, $3: 1, \mathrm{v}: \mathrm{v})$ to afford $552 \mathrm{mg}$ of $\mathbf{1 1 b}$ as a colorless liquid $(0.784 \mathrm{mmol}, 48 \%) .{ }^{1} \mathrm{H} \mathrm{NMR}$ $\left(\mathrm{CDCl}_{3}\right): \delta 7.70-7.65(\mathrm{~m}, 4 \mathrm{H}), 7.42-7.34(\mathrm{~m}, 6 \mathrm{H}), 4.97(\mathrm{~d}, J=2.0 \mathrm{~Hz}, 1 \mathrm{H}), 4.96(\mathrm{~d}, J=2.4 \mathrm{~Hz}$, $1 \mathrm{H}), 4.90(\mathrm{~d}, J=6.0 \mathrm{~Hz}, 1 \mathrm{H}), 4.76(\mathrm{~m}, 3 \mathrm{H}), 4.62(\mathrm{~m}, 1 \mathrm{H}), 4.50(\mathrm{~m}, 2 \mathrm{H}), 4.46(\mathrm{~m}, 1 \mathrm{H}), 3.98-3.73$ $(\mathrm{m}, 5 \mathrm{H}), 3.52(\mathrm{~m}, 2 \mathrm{H}), 3.43-3.23(\mathrm{~m}, 14 \mathrm{H}), 1.05(\mathrm{~s}, 9 \mathrm{H}) .{ }^{13} \mathrm{C} \mathrm{NMR}\left(\mathrm{CDCl}_{3}\right): \delta 135.99(\mathrm{~s})$, 135.85 (s), 133.79 (s), 133.76 (s), 132.48 (s), 130.08 (s), 129.97 (s), 129.91 (s), 129.89 (s), $128.10(\mathrm{~s}), 127.99(\mathrm{~s}), 127.81(\mathrm{~s}), 127.77(\mathrm{~s}), 99.14(\mathrm{~s}), 99.09(\mathrm{~s}), 98.86(\mathrm{~s}), 98.67(\mathrm{~s}), 98.38$ (s), $97.78(\mathrm{~s}), 97.55(\mathrm{~s}), 78.85(\mathrm{~m}), 78.04(\mathrm{~s}), 77.76(\mathrm{~s}), 76.42(\mathrm{~m}), 75.38(\mathrm{~s}), 75.31(\mathrm{~s}), 75.23$ (s), $73.54(\mathrm{~d}, J=7.68 \mathrm{~Hz}), 56.68(\mathrm{~d}, J=3.84 \mathrm{~Hz}), 56.63(\mathrm{~s}), 56.43(\mathrm{~s}), 53.10(\mathrm{~d}, J=6.16 \mathrm{~Hz})$, $52.46(\mathrm{~d}, J=6.97 \mathrm{~Hz}), 27.13(\mathrm{~s}), 27.10(\mathrm{~s}), 19.11(\mathrm{~s}), 19.08(\mathrm{~s}) .{ }^{31} \mathrm{P}$ NMR $\left(\mathrm{CDCl}_{3}\right): \delta 19.57$ (d, $J=61.88 \mathrm{~Hz}), 18.91(\mathrm{~d}, J=64.15 \mathrm{~Hz}) .{ }^{19} \mathrm{~F} \mathrm{NMR}\left(\mathrm{CDCl}_{3}\right): \delta-249.64(\mathrm{~m}) . \mathrm{MS}(\mathrm{ESI}) \mathrm{m} / \mathrm{z}$ $705.3\left(\mathrm{M}^{+}+1,100.00\right)$. HRMS (MALDI), $\mathrm{M}^{+}+\mathrm{Na}$, Found: 727.2685 ; calcd for $\mathrm{C}_{32} \mathrm{H}_{50} \mathrm{FNaO}_{12} \mathrm{PSi}, 727.2691$.

\section{D-3-(Methyl fluoromethylphosphonate)-2,4,5,6-O-tetrakis(methoxymethylene)-myo- inositol (12b)}

A solution of $\mathbf{1 1 b}$ (40 mg, $0.057 \mathrm{mmol})$ in THF ( $1 \mathrm{~mL}$ ) was treated with tetrabutylammoniumfluoride trihydrate $(36 \mathrm{mg}, 0.114 \mathrm{mmol})$ and acetic acid $(7 \mu \mathrm{L}, 0.114$ $\mathrm{mmol}$ ) at rt. After stirring for $12 \mathrm{~h}$, TLC indicated that the reaction was complete; solvent was evaporated in vacuo and the crude product was purified by passage through a short silica column ( $n$-hexane-acetone, 1:1, v:v) to afford $15 \mathrm{mg}$ of $\mathbf{1 2 b}$ as a colorless liquid $(0.032 \mathrm{mmol}$, 56\%). ${ }^{1} \mathrm{H} \mathrm{NMR}\left(\mathrm{CDCl}_{3}\right): \delta 4.86-4.68(\mathrm{~m}, 10 \mathrm{H}), 4.32(\mathrm{~m}, 1 \mathrm{H}), 4.17(\mathrm{~m}, 1 \mathrm{H}), 3.98(\mathrm{~m}, 1 \mathrm{H})$, 
$3.87(\mathrm{dd}, J=10.8,3.2 \mathrm{~Hz}, 3 \mathrm{H}), 3.65(\mathrm{t}, J=9.6 \mathrm{~Hz}, 1 \mathrm{H}), 3.41-3.34(\mathrm{~m}, 12 \mathrm{H}), 3.20(\mathrm{~m}, 2$

H). ${ }^{13} \mathrm{C} \mathrm{NMR}\left(\mathrm{CDCl}_{3}\right): \delta 98.73(\mathrm{~s}), 98.66(\mathrm{~s}), 98.48(\mathrm{~s}), 98.38(\mathrm{~s}), 98.18(\mathrm{~s}), 83.40(\mathrm{~s}), 83.00$ (s), $78.72(\mathrm{~d}, J=90.09 \mathrm{~Hz}), 78.33(\mathrm{~d}, J=90.09 \mathrm{~Hz}), 76.10(\mathrm{~d}, J=10.00 \mathrm{~Hz}), 70.43(\mathrm{~d}, J=6.16$ Hz), 58.68 (s), 56.65 (s), 56.52 (s), 56.37 (s), 56.12 (s), 55.91 (s), 55.85 (s), 53.52 (s), 53.11 (s). ${ }^{31} \mathrm{P} \mathrm{NMR}\left(\mathrm{CDCl}_{3}\right): \delta 34.60(\mathrm{~d}, J=62.05 \mathrm{~Hz}), 33.36(\mathrm{~d}, J=65.12 \mathrm{~Hz}) .{ }^{19} \mathrm{~F}$ NMR $\left(\mathrm{CDCl}_{3}\right): \delta-249.36(\mathrm{dt}, J=60.19,45.88 \mathrm{~Hz}),-250.08(\mathrm{dt}, J=62.78,45.88 \mathrm{~Hz})$. MS (CI) $\mathrm{m} /$ $z$ 467.2 ( $\left.\mathrm{M}^{+}+1,100.00\right)$. HRMS (MALDI), $\mathrm{M}^{+}+\mathrm{Na}$, Found: 489.1540; calcd for $\mathrm{C}_{16} \mathrm{H}_{32} \mathrm{FNaO}_{12} \mathrm{P}, 489.1508$.

\section{D-O-(1,2-Di-O-oleoyl-sn-(2S)-glycerol-3-O-methylphospho)-3-(methyl fluoromethylphosphonate)-2,4,5,6-O-tetrakis(methoxymethylene)-myo-inositol (14a)}

$N, N$-diisopropyl- $O$-methyl- $O$-(di-(2S)-oleoyl-sn-glycerol)phosphoramidite (77 mg, 0.093 mmol) was added under an argon atmosphere to a solution of $\mathbf{1 2 b}(29 \mathrm{mg}, 0.062 \mathrm{mmol})$ and $1 H$-tetrazole $(0.73 \mathrm{~mL}, 3 \% \mathrm{wt}, 0.249 \mathrm{mmol})$ in $4 \mathrm{~mL}$ dry $\mathrm{CH}_{3} \mathrm{CN}-\mathrm{THF}(1: 1, \mathrm{v}: \mathrm{v})$. After stirring for $20 \mathrm{~h}$ at rt, oxidation was performed with $\left(\mathrm{n}-\mathrm{C}_{4} \mathrm{H}_{9}\right)_{4} \mathrm{NIO}_{4}(40 \mathrm{mg}, 0.093 \mathrm{mmol})$ at $-20^{\circ} \mathrm{C}$ for $1 \mathrm{~h}$. The reaction mixture was warmed-up to rt for additional $30 \mathrm{~min}$, and after aqueous work-up the crude product was purified by FC ( $n$-hexane-acetone, 2:1, v:v) to give $60 \mathrm{mg}$ of pure product $14 \mathrm{a}$ as colorless oil $(0.052 \mathrm{mmol}, 83 \%) .{ }^{1} \mathrm{H} \mathrm{NMR}\left(\mathrm{CDCl}_{3}\right): \delta 5.30(\mathrm{~m}, 4 \mathrm{H}), 5.21$ $(\mathrm{m}, 1 \mathrm{H}), 4.84-4.67(\mathrm{~m}, 10 \mathrm{H}), 4.32-4.09(\mathrm{~m}, 8 \mathrm{H}), 3.93(\mathrm{~m}, 2 \mathrm{H}), 3.86(\mathrm{~d}, J=11.2 \mathrm{~Hz}, 3 \mathrm{H}), 3.78$ $(\mathrm{dd}, J=10.8,3.2 \mathrm{~Hz}, 3 \mathrm{H}), 3.41(\mathrm{~m}, 12 \mathrm{H}), 2.29(\mathrm{~m}, 4 \mathrm{H}), 1.96(\mathrm{~m}, 8 \mathrm{H}), 1.57(\mathrm{~m}, 4 \mathrm{H}), 1.26(\mathrm{~m}$, $42 \mathrm{H}), 0.84(\mathrm{t}, J=7.2 \mathrm{~Hz}, 6 \mathrm{H}) .{ }^{13} \mathrm{C}$ NMR $\left(\mathrm{CDCl}_{3}\right): \delta 173.16(\mathrm{~s}), 172.78(\mathrm{~s}), 129.96(\mathrm{~s}), 129.64$ (s), $98.86(\mathrm{~s}), 98.70(\mathrm{~s}), 98.42(\mathrm{~s}), 98.18(\mathrm{~s}), 97.93(\mathrm{~s}), 78.94(\mathrm{~d}, J=6.16 \mathrm{~Hz}), 76.39(\mathrm{~m}), 75.40$ $(\mathrm{d}, J=22.32 \mathrm{~Hz}), 75.30(\mathrm{~d}, J=22.42 \mathrm{~Hz}), 69.34(\mathrm{~m}), 65.82(\mathrm{~s}), 65.51(\mathrm{~s}), 61.56(\mathrm{~s}), 56.73(\mathrm{~s})$, $56.56(\mathrm{~s}), 55.83(\mathrm{~s}), 55.56(\mathrm{~s}), 54.80(\mathrm{~d}, J=6.16 \mathrm{~Hz}), 54.60(\mathrm{~d}, J=8.08 \mathrm{~Hz}), 53.60(\mathrm{~d}, J=6.06$ $\mathrm{Hz}), 53.25(\mathrm{~d}, J=6.16 \mathrm{~Hz}), 34.04(\mathrm{~s}), 33.92(\mathrm{~s}), 31.85(\mathrm{~s}), 29.70(\mathrm{~s}), 29.67(\mathrm{~s}), 29.47(\mathrm{~s}), 29.26$ $(\mathrm{s}), 29.17(\mathrm{~s}), 29.15(\mathrm{~s}), 29.08(\mathrm{~s}), 29.05(\mathrm{~s}), 29.02(\mathrm{~s}), 27.16(\mathrm{~s}), 27.12(\mathrm{~s}), 24.75(\mathrm{~s}), 22.63(\mathrm{~s})$, $14.06(\mathrm{~s}) .{ }^{31} \mathrm{P} \mathrm{NMR}\left(\mathrm{CDCl}_{3}\right): \delta 19.53(\mathrm{~d}, J=63.02 \mathrm{~Hz}), 19.13(\mathrm{~d}, J=67.39 \mathrm{~Hz}), 0.57(\mathrm{~s}) .{ }^{19} \mathrm{~F}$ NMR $\left(\mathrm{CDCl}_{3}\right): \delta-249.23(\mathrm{~m}),-250.08(\mathrm{~m})$. MS (ESI) $\mathrm{m} / z 1163.7\left(\mathrm{M}^{+}+1,100.00\right)$. HRMS (MALDI), $\mathrm{M}^{+}+\mathrm{Na}$, Found: 1185.6608; calcd for $\mathrm{C}_{56} \mathrm{H}_{105} \mathrm{FNaO}_{19} \mathrm{P}_{2}, 1185.6607$.

\section{D-O-(1,2-Di-O-oleoyl-sn-(2S)-glycerol-3-phospho)-3-(fluoromethylphosphonate)-myo- inositol, (16a)}

The phosphate 14a (32 $\mathrm{mg}, 0.028 \mathrm{mmol})$ was dried and reacted with TMSBr and then hydrolyzed in aqueous $\mathrm{MeOH}$ and dried as described above for 15a. Ethanethiol $(1 \mathrm{~mL})$ was added, the solution was kept at $\mathrm{rt}$ for $1 \mathrm{~h}$, and concentrated to yield the crude product. Chromatography on silica gel $\left(\mathrm{CHCl}_{3}-\mathrm{CH}_{3} \mathrm{OH}-\mathrm{NH}_{4} \mathrm{OH}(2.0 \mathrm{M}), 65: 25: 3\right.$, v:v:v) provided 20 $\mathrm{mg}$ of pure product $16 \mathrm{a}(0.021 \mathrm{mmol}, 75 \%) .{ }^{1} \mathrm{H}$ NMR $\left(\mathrm{CDCl}_{3}-\mathrm{CD}_{3} \mathrm{OD}, 3: 2, \mathrm{v}: \mathrm{v}\right): \delta 5.29(\mathrm{~m}$, $4 \mathrm{H}), 5.21(\mathrm{~m}, 1 \mathrm{H}), 4.78(\mathrm{~m}, 1 \mathrm{H}), 4.73(\mathrm{~m}, 1 \mathrm{H}), 4.66(\mathrm{~m}, 1 \mathrm{H}), 4.14(\mathrm{~m}, 4 \mathrm{H}), 3.77(\mathrm{~m}, 2 \mathrm{H}), 3.38$ $(\mathrm{m}, 2 \mathrm{H}), 2.28(\mathrm{~m}, 4 \mathrm{H}), 1.96(\mathrm{~m}, 8 \mathrm{H}), 1.56(\mathrm{~m}, 4 \mathrm{H}), 1.24(\mathrm{~m}, 42 \mathrm{H}), 0.83(\mathrm{t}, J=7.2 \mathrm{~Hz}$, $6 \mathrm{H}) .{ }^{13} \mathrm{C}$ NMR $\left(\mathrm{CDCl}_{3}-\mathrm{CD}_{3} \mathrm{OD}, 3: 2\right.$, v:v): $\delta 174.26(\mathrm{~s}), 173.87$ (s), $130.27(\mathrm{~s}), 129.97$ (s), $98.10(\mathrm{~s}), 71.70(\mathrm{~m}), 71.24(\mathrm{~m}), 70.12(\mathrm{~s}), 70.04(\mathrm{~s}), 65.37(\mathrm{~m}), 62.43(\mathrm{~m}), 56.01(\mathrm{~s}), 34.36(\mathrm{~s})$, 30.03 (s), 29.80 (s), 29.60 (s), 29.58 (s), 29.42 (m), 27.47 (s), 27.44 (s), 25.12 (s), 22.9 (s), 14.22 (s). ${ }^{31} \mathrm{P} \mathrm{NMR}\left(\mathrm{CDCl}_{3}-\mathrm{CD}_{3} \mathrm{OD}, 3: 2\right.$, v:v): $\delta 21.25(\mathrm{~d}, J=63.02 \mathrm{~Hz}), 21.10(\mathrm{~d}, J=67.39$ $\mathrm{Hz}), 3.61$ (s), 3.36 (s). ${ }^{19} \mathrm{~F} \mathrm{NMR}\left(\mathrm{CDCl}_{3}-\mathrm{CD}_{3} \mathrm{OD}, 3: 2\right.$, v:v): $\delta-245.96(\mathrm{~m})$. MS (ESI) $\mathrm{m} / \mathrm{z}$ 1015.6 ( $\left.\mathrm{M}^{+}+\mathrm{Na}, \mathrm{C}_{46} \mathrm{H}_{91} \mathrm{FN}_{2} \mathrm{NaO}_{15} \mathrm{P}_{2}\right)$. HRMS (MALDI), $\mathrm{M}^{+}+\mathrm{Na}$, Found: 1015.5803; calcd for $\mathrm{C}_{46} \mathrm{H}_{91} \mathrm{FN}_{2} \mathrm{NaO}_{15} \mathrm{P}_{2}, 1015.5776$.

\section{D-O-(1,2-Di-O-palmitoyl-sn-(2S)-glycerol-3-O-methylphospho)-3-(methyl fluoromethylphosphonate)-2,4,5,6-O-tetrakis(methoxymethylene)-myo-inositol (14b)}

$N, N$-diisopropyl- $O$-methyl- $O$-(di-( $2 S$ )-palmitoyl-sn-glycerol)phosphoramidite $(90 \mathrm{mg}, 0.123$ $\mathrm{mmol}$ ) was added under an argon atmosphere to a solution of $\mathbf{1 2 b}(38 \mathrm{mg}, 0.082 \mathrm{mmol})$ and 
$1 H$-tetrazole $(1.0 \mathrm{~mL}, 3 \%$ wt, $0.320 \mathrm{mmol})$ in $4 \mathrm{~mL}$ dry $\mathrm{CH}_{3} \mathrm{CN}$-THF (1:1, v:v). After stirring for $20 \mathrm{~h}$ at rt, oxidation was performed with $\left(n-\mathrm{C}_{4} \mathrm{H}_{9}\right)_{4} \mathrm{NIO}_{4}(60 \mathrm{mg}, 0.123 \mathrm{mmol})$ at $-20^{\circ} \mathrm{C}$ for $1 \mathrm{~h}$. The reaction mixture was warmed to $\mathrm{rt}$ for an additional $30 \mathrm{~min}$, and after aqueous work-up the crude product was purified by FC ( $n$-hexane-acetone, 2:1, v:v) to give $49 \mathrm{mg}$ of pure 14b as colorless oil (49 mg, $0.044 \mathrm{mmol}, 54 \%) .{ }^{1} \mathrm{H} \mathrm{NMR}\left(\mathrm{CDCl}_{3}\right): \delta 5.22(\mathrm{~m}, 1 \mathrm{H})$, $4.85-4.69(\mathrm{~m}, 10 \mathrm{H}), 4.34-4.10(\mathrm{~m}, 8 \mathrm{H}), 3.95(\mathrm{t}, J=9.6 \mathrm{~Hz}, 2 \mathrm{H}), 3.87(\mathrm{~d}, J=10.8 \mathrm{~Hz}, 1 \mathrm{H}), 3.79$ $(\mathrm{d}, J=11.2 \mathrm{~Hz}, 1 \mathrm{H}), 3.43-3.39(\mathrm{~m}, 12 \mathrm{H}), 2.29(\mathrm{~m}, 4 \mathrm{H}), 1.58(\mathrm{~m}, 8 \mathrm{H}), 1.23(\mathrm{~m}, 48 \mathrm{H}), 0.86(\mathrm{t}$, $J=7.2 \mathrm{~Hz}, 6 \mathrm{H}) .{ }^{13} \mathrm{C} \mathrm{NMR}\left(\mathrm{CDCl}_{3}\right): \delta 173.19(\mathrm{~s}), 172.80(\mathrm{~s}), 98.90(\mathrm{~s}), 98.53(\mathrm{~s}), 98.43(\mathrm{~s})$, $98.35(\mathrm{~s}), 98.03(\mathrm{~s}), 97.83(\mathrm{~s}), 79.13(\mathrm{~d}, J=13.78 \mathrm{~Hz}), 77.21(\mathrm{~s}), 76.90(\mathrm{~s}), 76.35(\mathrm{~s}), 74.24$ (dd, $J=31.48,6.13 \mathrm{~Hz}), 69.44(\mathrm{~s}), 69.35$ (s), 65.75 (s), 65.57 (s), 61.60 (s), 56.77 (s), 56.64 (s), $56.55(\mathrm{~s}), 56.50(\mathrm{~s}), 55.75(\mathrm{~s}), 53.75(\mathrm{~s}), 52.18(\mathrm{dd}, J=35.30,6.13 \mathrm{~Hz}), 34.08(\mathrm{~s}), 33.96$ (s), $31.88(\mathrm{~s}), 29.65(\mathrm{~s}), 29.63(\mathrm{~s}), 29.61(\mathrm{~s}), 29.45(\mathrm{~s}), 29.31(\mathrm{~s}), 29.25(\mathrm{~s}), 29.22(\mathrm{~s}), 29.09(\mathrm{~s})$, $29.06(\mathrm{~s}), 24.78(\mathrm{~s}), 22.64(\mathrm{~s}), 14.07(\mathrm{~s}), 11.03(\mathrm{dd}, J=148.83,12.27 \mathrm{~Hz}) .{ }^{31} \mathrm{P}$ NMR $\left(\mathrm{CDCl}_{3}\right): \delta 19.53(\mathrm{~d}, J=61.88 \mathrm{~Hz}), 0.74(\mathrm{~s}) .{ }^{19} \mathrm{~F} \mathrm{NMR}\left(\mathrm{CDCl}_{3}\right): \delta-249.09(\mathrm{~m}) . \mathrm{MS}(\mathrm{ESI}) \mathrm{m} /$ $z$ 1133.6 $\left(\mathrm{M}^{+}+1,100.00\right)$. HRMS (MALDI), $\mathrm{M}^{+}+\mathrm{Na}$, Found: 1133.6325 ; calcd for $\mathrm{C}_{52} \mathrm{H}_{101} \mathrm{FNaO}_{19} \mathrm{P}_{2}, 1133.6294$.

\section{D-O-(1,2-Di-O-palmitoyl-sn-(2S)-glycerol-3-phospho)-3-(fluoromethylphosphonate)-myo- inositol (16b)}

The phosphate 14b (35 mg, $0.032 \mathrm{mmol}$ ) was dried, treated with TMSBr, the resulting ethers hydrolyzed in aqueous $\mathrm{MeOH}$, and the crude product dried as described above for 15a. Ethanethiol $(1 \mathrm{~mL})$ was added, the solution was kept at $\mathrm{rt}$ for $1 \mathrm{~h}$, and concentrated to yield the crude product. $\mathrm{FC}$ on silica gel gel $\left(\mathrm{CHCl}_{3}-\mathrm{CH}_{3} \mathrm{OH}-\mathrm{NH}_{4} \mathrm{OH}(2.0 \mathrm{M}), 65: 25: 3\right.$, v:v:v) provided $21 \mathrm{mg}$ of $\mathbf{1 6 b}(0.022 \mathrm{mmol}, 67 \%) .{ }^{1} \mathrm{H}$ NMR $\left(\mathrm{CDCl}_{3}-\mathrm{CD}_{3} \mathrm{OD}, 3: 2, \mathrm{v}: \mathrm{v}\right): \delta 5.21(\mathrm{~m}, 1 \mathrm{H}), 4.78$ $(\mathrm{m}, 1 \mathrm{H}), 4.73(\mathrm{~m}, 1 \mathrm{H}), 4.66(\mathrm{~m}, 1 \mathrm{H}), 4.14(\mathrm{~m}, 4 \mathrm{H}), 3.77(\mathrm{~m}, 2 \mathrm{H}), 3.38(\mathrm{~m}, 2 \mathrm{H}), 2.28(\mathrm{~m}, 4 \mathrm{H})$, $1.56(\mathrm{~m}, 4 \mathrm{H}), 1.24(\mathrm{~m}, 48 \mathrm{H}), 0.83(\mathrm{t}, J=7.2 \mathrm{~Hz}, 6 \mathrm{H}) .{ }^{13} \mathrm{C} \mathrm{NMR}\left(\mathrm{CDCl}_{3}-\mathrm{CD}_{3} \mathrm{OD}, 3: 2\right.$, v:v): $\delta 174.26(\mathrm{~s}), 173.87(\mathrm{~s}), 98.10(\mathrm{~s}), 71.70(\mathrm{~m}), 71.24(\mathrm{~m}), 70.12(\mathrm{~s}), 70.04(\mathrm{~s}), 65.37(\mathrm{~m}), 62.43$ $(\mathrm{m}), 56.01(\mathrm{~s}), 34.36(\mathrm{~s}), 30.03(\mathrm{~s}), 29.80(\mathrm{~s}), 29.60(\mathrm{~s}), 29.58(\mathrm{~s}), 29.42(\mathrm{~m}), 27.47(\mathrm{~s}), 27.44$ (s), $25.12(\mathrm{~s}), 22.9(\mathrm{~s}), 14.22(\mathrm{~s}) .{ }^{31} \mathrm{P} \mathrm{NMR}\left(\mathrm{CDCl}_{3}-\mathrm{CD}_{3} \mathrm{OD}, 3: 2, \mathrm{v}: \mathrm{v}\right): \delta 21.25(\mathrm{~d}, J=63.02$ $\mathrm{Hz}), 21.10(\mathrm{~d}, J=67.39 \mathrm{~Hz}), 3.61(\mathrm{~s}), 3.36(\mathrm{~s}) .{ }^{19} \mathrm{~F} \mathrm{NMR}\left(\mathrm{CDCl}_{3}-\mathrm{CD}_{3} \mathrm{OD}, 3: 2, \mathrm{v}: \mathrm{v}\right): \delta-245.96$ (m). MS (ESI) $\mathrm{m} / z, 959.63\left(\mathrm{M}^{+}+\mathrm{NH}_{4}, \mathrm{C}_{42} \mathrm{H}_{91} \mathrm{FN}_{3} \mathrm{O}_{15} \mathrm{P}_{2}, 100.00\right)$. HRMS (MALDI), $\mathrm{M}^{+}+\mathrm{Na}$, Found: 958.5884; calcd for $\mathrm{C}_{42} \mathrm{H}_{91} \mathrm{FN}_{3} \mathrm{O}_{15} \mathrm{P}_{2}$, 958.5909.

\section{D-O-(1,2-Di-O-butanoyl-sn-(2S)-glycerol-3-O-methylphospho)-3-(methyl fluoromethylphosphonate)-2,4,5,6-O-tetrakis(methoxymethylene)-myo-inositol (14c)}

To a solution of alcohol $\mathbf{1 2 b}(12 \mathrm{mg}, 0.026 \mathrm{mmol})$ in dry THF $(0.5 \mathrm{~mL})$ was added $N, N$ diisopropyl- $O$-(methyl- $O$-di-butanoyl-sn-( $2 S$ )-glycerol)phosphoramidite $(145 \mathrm{mg}, 0.039$ $\mathrm{mmol})$ and $1 \mathrm{H}$-tetrazole $(0.31 \mathrm{~mL}, 3 \% \mathrm{wt}, 0.104 \mathrm{mmol})$. The mixture was stirred at $\mathrm{rt}$ for 16 h. Then oxidation was performed with $\left(\mathrm{n}-\mathrm{C}_{4} \mathrm{H}_{9}\right)_{4} \mathrm{NIO}_{4}(17 \mathrm{mg}, 0.039 \mathrm{mmol})$ at $-20^{\circ} \mathrm{C}$ for $1 \mathrm{~h}$. The reaction mixture was warmed to $\mathrm{rt}$ for an additional $30 \mathrm{~min}$. The solution was diluted with methylene chloride $(20 \mathrm{~mL})$ and washed with $10 \%$ sodium bisulfite. The organic layer was concentrated and the residue was purified by FC ( $n$-hexane-acetone, 2:1, v:v) to give $14 \mathrm{mg}$ of pure $14 \mathbf{c}$ as colorless oil $(0.018 \mathrm{mmol}, 70 \%) .{ }^{1} \mathrm{H} \mathrm{NMR}\left(\mathrm{CDCl}_{3}\right): \delta 5.23(\mathrm{~m}, 1 \mathrm{H}), 4.85-4.69(\mathrm{~m}$, $10 \mathrm{H}$ ), 4.34-4.07 (m, 8H), $3.94(\mathrm{t}, J=10.0 \mathrm{~Hz}, 2 \mathrm{H}), 3.87(\mathrm{t}, J=9.6 \mathrm{~Hz}, 3 \mathrm{H}), 3.97$ (dd, $J=5.6$, $4.4 \mathrm{~Hz}, 3 \mathrm{H}), 3.42-3.37(\mathrm{~m}, 12 \mathrm{H}), 2.29(\mathrm{~m}, 4 \mathrm{H}), 1.62(\mathrm{~m}, 4 \mathrm{H}), 0.93(\mathrm{t}, J=7.2 \mathrm{~Hz}, 3 \mathrm{H}), 0.90(\mathrm{t}$, $J=7.2 \mathrm{~Hz}, 3 \mathrm{H}) .{ }^{13} \mathrm{C} \mathrm{NMR}\left(\mathrm{CDCl}_{3}\right): \delta 173.06(\mathrm{~s}), 172.90(\mathrm{~s}), 98.89(\mathrm{~s}), 98.73(\mathrm{~s}), 98.46(\mathrm{~s})$, $97.96(\mathrm{~s}), 79.01(\mathrm{~s}), 76.44(\mathrm{~s}), 75.54(\mathrm{~s}), 69.34(\mathrm{~s}), 65.85$ (s), $61.56(\mathrm{~s}), 56.81(\mathrm{~s}), 56.59(\mathrm{~s})$, $55.87(\mathrm{~s}), 35.94(\mathrm{~s}), 35.83(\mathrm{~s}), 18.28(\mathrm{~s}), 13.60(\mathrm{~s}), 13.54(\mathrm{~s}) .{ }^{31} \mathrm{P} \mathrm{NMR}\left(\mathrm{CDCl}_{3}\right): \delta 19.55(\mathrm{dd}$, $J=60.75,3.24 \mathrm{~Hz}), 19.11(\mathrm{dd}, J=63.99,5.34 \mathrm{~Hz}), 0.74(\mathrm{~s}), 0.68(\mathrm{~s}), 0.59(\mathrm{~s}), 0.56(\mathrm{~s}) .{ }^{19} \mathrm{~F}$ $\operatorname{NMR}\left(\mathrm{CDCl}_{3}\right): \delta-249.26(\mathrm{~m}),-250.01(\mathrm{~m})$. MS (CI) $\mathrm{m} / z .775 .46\left(\mathrm{M}^{+}+1,100.00\right)$. HRMS (CI), $\mathrm{M}^{+}+1$, Found: 775.2751; calcd for $\mathrm{C}_{28} \mathrm{H}_{54} \mathrm{FO}_{19} \mathrm{P}_{2}, 775.2719$. 


\section{D-O-(1,2-Di-O-butanoyl-sn-(2S)-glycerol-3-phospho)-3-(fluoromethylphosphonate)-myo- inositol (16c)}

The phosphate $14 \mathrm{c}(17 \mathrm{mg}, 0.022 \mathrm{mmol})$ was dried, treated with TMSBr, the silyl ethers hydrolyzed in aqueous $\mathrm{MeOH}$, and the crude product dried as described above for 16a. Ethanethiol $(1 \mathrm{~mL})$ was added, the solution was kept at $\mathrm{rt}$ for $1 \mathrm{~h}$, and concentrated and the crude product was chromatographed on silica gel gel $\left(\mathrm{CHCl}_{3}-\mathrm{CH}_{3} \mathrm{OH}-\mathrm{NH}_{4} \mathrm{OH}(2.0 \mathrm{M})\right.$, 65:25:3, v:v:v) to give pure product as a white powder (9 mg, $0.015 \mathrm{mmol}, 68 \%) .{ }^{1} \mathrm{H}$ NMR $\left(\mathrm{CDCl}_{3}-\mathrm{CD}_{3} \mathrm{OD}, 3: 2, \mathrm{v}: \mathrm{v}\right): \delta 5.18(\mathrm{~m}, 1 \mathrm{H}), 4.77(\mathrm{~m}, 1 \mathrm{H}), 4.66(\mathrm{dd}, J=12.0,5.2 \mathrm{~Hz}, 1 \mathrm{H})$, 4.43-4.15 (m, 2H), 4.12-4.07 (m, 4H), $3.95(\mathrm{~m}, 1 \mathrm{H}), 3.74(\mathrm{~m}, 1 \mathrm{H}), 3.15(\mathrm{~m}, 2 \mathrm{H}), 2.23(\mathrm{~m}, 4 \mathrm{H})$, $1.56(\mathrm{~m}, 4 \mathrm{H}), 0.86(\mathrm{~m}, 6 \mathrm{H}) .{ }^{13} \mathrm{C} \mathrm{NMR}\left(\mathrm{CDCl}_{3}\right): \delta 174.46(\mathrm{~s}), 174.07(\mathrm{~s}), 130.44(\mathrm{~s}), 130.16$ (s), $74.70(\mathrm{~d}, J=9.16 \mathrm{~Hz}), 71.51(\mathrm{~s}), 71.15(\mathrm{~s}), 70.36(\mathrm{~d}, J=7.64 \mathrm{~Hz}), 65.61(\mathrm{~s}), 62.77(\mathrm{~s})$, $34.61(\mathrm{~s}), 34.49$ (s), 32.40 (s), $30.23(\mathrm{~s}), 30.00$ (s), $29.81(\mathrm{~s}), 29.77$ (s), $29.72(\mathrm{~s}), 29.70(\mathrm{~s})$, $29.61(\mathrm{~s}), 29.55$ (s), 27.65 (s), 25.34 (s), 23.13 (s), 14.32 (s). ${ }^{31} \mathrm{P} \mathrm{NMR}\left(\mathrm{CDCl}_{3} / \mathrm{CD}_{3} \mathrm{OD}, 3 / 2\right.$, $\mathrm{v} / \mathrm{v}): \delta 21.49(\mathrm{~s}), 21.09(\mathrm{~s}), 3.35(\mathrm{~s}), 3.32(\mathrm{~s}) .{ }^{19} \mathrm{~F}$ NMR $\left(\mathrm{CDCl}_{3}-\mathrm{CD}_{3} \mathrm{OD}, 3: 2, \mathrm{v}: \mathrm{v}\right): \delta-246.28$ (m). MS (ESI) $m / z 571.26\left(\mathrm{M}^{+}+1,18.00\right)$. HRMS(MALDI), $\mathrm{M}^{+}+\mathrm{Na}$, Found: $593.1199 \mathrm{Calcd}$ for $\mathrm{C}_{18} \mathrm{H}_{33} \mathrm{FNaO}_{15} \mathrm{P}_{2}, 593.1176$.

\section{N,N-Diisopropyl-O-cyanoethyl-O-(di-oleoyl-sn-(2S)-glycerol)phosphonamidite (20a)}

A solution of $53 \mathrm{mg}$ of 2-cyanoethyl- $N, N$-diisopropylchlorophosphoramidite $(0.226 \mathrm{mmol})$ and $35 \mathrm{mg}$ ( $47 \mu \mathrm{L}, 0.271 \mathrm{mmol}$ ) of DIPEA in $3 \mathrm{~mL}$ anhydrous $\mathrm{CH}_{2} \mathrm{Cl}_{2}$ was cooled to $0^{\circ} \mathrm{C}$ under nitrogen. To this solution, $140 \mathrm{mg}(0.226 \mathrm{mmol}) 1,2$-di-oleoyl-sn-(2S)-glycerol was added with vigorous stirring. After stirring at $0^{\circ} \mathrm{C}$ for $1 \mathrm{~h}$ and stirring at $\mathrm{rt}$ for $3 \mathrm{~h}$ under nitrogen, the solution was separated from the white precipitate. FC on silica gel (hexane-EtOAc-TEA, 100:10:1, v:v:v) gave $96 \mathrm{mg}$ of $\mathbf{2 0 a}(0.118 \mathrm{mmol}, 52 \%)$ as colorless oil. ${ }^{1} \mathrm{H} \mathrm{NMR}\left(\mathrm{CDCl}_{3}\right): \delta$ $5.32(\mathrm{~m}, 4 \mathrm{H}), 5.17(\mathrm{~m}, 1 \mathrm{H}), 4.32(\mathrm{~m}, 1 \mathrm{H}), 4.13(\mathrm{~m}, 1 \mathrm{H}), 3.85-3.52(\mathrm{~m}, 6 \mathrm{H}), 2.61(\mathrm{t}, J=6.8 \mathrm{~Hz}$, $2 \mathrm{H}), 2.28(\mathrm{~m}, 4 \mathrm{H}), 1.98(\mathrm{~m}, 8 \mathrm{H}), 1.58(\mathrm{~m}, 4 \mathrm{H}), 1.26(\mathrm{~m}, 42 \mathrm{H}), 1.14(\mathrm{~m}, 12 \mathrm{H}), 0.86(\mathrm{t}, J=7.2$ $\mathrm{Hz}, 6 \mathrm{H}) .{ }^{13} \mathrm{C} \mathrm{NMR}\left(\mathrm{CDCl}_{3}\right): \delta 173.35(\mathrm{~s}), 172.96(\mathrm{~s}), 129.99(\mathrm{~s}), 129.69(\mathrm{~s}), 62.36(\mathrm{~s}), 61.77$ $(\mathrm{s}), 61.62(\mathrm{~s}), 58.57(\mathrm{~s}), 58.48(\mathrm{~s}), 58.30(\mathrm{~s}), 43.20(\mathrm{~s}), 43.08(\mathrm{~s}), 34.28(\mathrm{~s}), 34.08(\mathrm{~s}), 33.36(\mathrm{~s})$, $31.88(\mathrm{~s}), 29.75(\mathrm{~s}), 29.70(\mathrm{~s}), 29.51(\mathrm{~s}), 29.31(\mathrm{~s}), 29.19(\mathrm{~s}), 29.12(\mathrm{~s}), 28.96(\mathrm{~s}), 27.20(\mathrm{~s})$, $27.16(\mathrm{~s}), 24.89$ (s), $24.86(\mathrm{~s}), 24.60$ (s), 24.53 (s), $22.66(\mathrm{~s}), 20.38$ (s), $20.31(\mathrm{~s}), 14.10$ (s). ${ }^{31} \mathrm{P}$ NMR $\left(\mathrm{CDCl}_{3}\right): \delta 150.61(\mathrm{~s}), 150.46$ (s). MS (CI) $\mathrm{m} / z 821.6\left(\mathrm{M}^{+}+1, \mathrm{C}_{48} \mathrm{H}_{90} \mathrm{~N}_{2} \mathrm{O}_{6} \mathrm{P}\right.$, 41.22). HRMS(CI), $\mathrm{M}^{+}+1$, Found: 821.6562 Calcd for $\mathrm{C}_{48} \mathrm{H}_{90} \mathrm{~N}_{2} \mathrm{O}_{6} \mathrm{P}, 821.6537$.

\section{$\mathrm{N}, \mathrm{N}$-Diisopropyl-O-cyanoethyl-O-(di-palmitoyl-sn-(2S)-glycerol)phosphonamidite (20b)}

A solution of $38 \mathrm{mg}(0.162 \mathrm{mmol})$ of 2-cyanoethyl- $N, N$-diisopropylchlorophosphoramidite and $25 \mathrm{mg}(34 \mu \mathrm{L}, 0.194 \mathrm{mmol})$ of DIPEA in $3 \mathrm{~mL}$ anhydrous $\mathrm{CH}_{2} \mathrm{Cl}_{2}$ was cooled to $0^{\circ} \mathrm{C}$ under nitrogen. To this solution, (92 mg, $0.162 \mathrm{mmol}$ ) 1,2-di-palmitoyl-sn-(2S)-glycerol was added with vigorous stirring. After stirring at $0^{\circ} \mathrm{C}$ for $1 \mathrm{~h}$ and stirring at $\mathrm{rt}$ for $3 \mathrm{~h}$ under nitrogen, the solution was separated from the white precipitate. FC on silica gel (hexane-EtOAc-TEA, 100:10:1, v:v:v) gave $67 \mathrm{mg}$ of $\mathbf{2 0 b}(0.087 \mathrm{mmol}, 54 \%)$ as a white solid. ${ }^{1} \mathrm{H}$ NMR $\left(\mathrm{CDCl}_{3}\right)$ : $\delta 5.16(\mathrm{~m}, 1 \mathrm{H}), 4.31(\mathrm{~m}, 1 \mathrm{H}), 4.15(\mathrm{~m}, 1 \mathrm{H}), 3.85-3.54(\mathrm{~m}, 6 \mathrm{H}), 2.60(\mathrm{t}, J=6.8 \mathrm{~Hz}, 2 \mathrm{H}), 2.29$ $(\mathrm{m}, 4 \mathrm{H}), 1.59(\mathrm{~m}, 4 \mathrm{H}), 1.26(\mathrm{~m}, 48 \mathrm{H}), 1.26(\mathrm{~m}, 42 \mathrm{H}), 1.14(\mathrm{~m}, 12 \mathrm{H}), 0.85(\mathrm{t}, J=7.2 \mathrm{~Hz}$, $6 \mathrm{H}) .{ }^{13} \mathrm{C} \mathrm{NMR}\left(\mathrm{CDCl}_{3}\right): \delta 173.36(\mathrm{~s}), 172.97(\mathrm{~s}), 117.50(\mathrm{~s}), 70.56(\mathrm{~d}, J=3.84 \mathrm{~Hz}) 62.34(\mathrm{~s})$, $61.76(\mathrm{~s}), 61.61(\mathrm{~s}), 61.44(\mathrm{~s}), 58.56(\mathrm{~s}), 58.48(\mathrm{~s}), 58.38(\mathrm{~s}), 58.29(\mathrm{~s}), 43.19(\mathrm{~s}), 43.06(\mathrm{~s})$, 34.29 (s), 34.10 (s), 33.35 (s), 31.90 (s), 29.67 (s), 29.63 (s), 29.61 (s), 29.47 (s), $29.34(\mathrm{~s})$, $29.28(\mathrm{~s}), 29.12(\mathrm{~s}), 29.09(\mathrm{~s}), 24.90(\mathrm{~s}), 24.87(\mathrm{~s}), 24.59(\mathrm{~s}), 24.52(\mathrm{~s}), 22.66(\mathrm{~s}), 20.37(\mathrm{~s})$, 20.29 (s), 14.09 (s). ${ }^{31} \mathrm{P}$ NMR $\left(\mathrm{CDCl}_{3}\right): \delta 150.60$ (s), 150.45 (s). MS (CI) $\mathrm{m} / z .69 .6\left(\mathrm{M}^{+}+1\right.$, 22.44). HRMS (CI), $\mathrm{M}^{+}$, Found: 768.6141; calcd for $\mathrm{C}_{44} \mathrm{H}_{85} \mathrm{~N}_{2} \mathrm{O}_{6} \mathrm{P}, 768.6145$. 


\section{N,N-Diisopropyl-O-cyanoethyl-O-(di-butanoyl-sn-(2S)-glycerol)phosphonamidite (20c)}

A solution of (220 mg, $0.931 \mathrm{mmol}$ ) 2-cyanoethyl- $N, N$-diisopropylchlorophosphoramidite and (144 mg, $200 \mu \mathrm{L}, 1.117 \mathrm{mmol}$ ) DIPEA in $5 \mathrm{~mL}$ anhydrous $\mathrm{CH}_{2} \mathrm{Cl}_{2}$ was cooled to $0^{\circ} \mathrm{C}$ under nitrogen. To this solution 1,2-di-butanoyl-sn-(2S)-glycerol (216 $\mathrm{mg}, 0.931 \mathrm{mmol})$ was added with vigorous stirring. After stirring at $0^{\circ} \mathrm{C}$ for $1 \mathrm{~h}$ and stirring at $\mathrm{rt}$ for $3 \mathrm{~h}$ under nitrogen, the solution was separated from the white precipitate. FC on silica gel (hexane:EtOAc:TEA, 100:10:1, v:v:v) gave $285 \mathrm{mg}$ of pure $20 \mathrm{c}(0.661 \mathrm{mmol}, 71 \%)$ as a colorless oil. ${ }^{1} \mathrm{H}$ NMR $\left(\mathrm{CDCl}_{3}\right): \delta 5.07(\mathrm{~m}, 1 \mathrm{H}), 4.22(\mathrm{~m}, 1 \mathrm{H}), 4.05(\mathrm{~m}, 1 \mathrm{H}), 3.76-3.47(\mathrm{~m}, 6 \mathrm{H}), 2.54(\mathrm{t}, J=6.4 \mathrm{~Hz}$, 2H), $2.19(\mathrm{~m}, 4 \mathrm{H}), 1.53(\mathrm{~m}, 4 \mathrm{H}), 1.06(\mathrm{~m}, 12 \mathrm{H}), 0.84(\mathrm{t}, J=7.2 \mathrm{~Hz}, 3 \mathrm{H}), 0.81(\mathrm{t}, J=7.2 \mathrm{~Hz}$, $3 \mathrm{H}) .{ }^{13} \mathrm{C} \mathrm{NMR}\left(\mathrm{CDCl}_{3}\right): \delta 172.78(\mathrm{~s}), 172.43(\mathrm{~s}), 117.32(\mathrm{~s}), 70.34(\mathrm{dd}, J=7.68,3.84 \mathrm{~Hz})$, $62.01(\mathrm{~d}, J=1.52 \mathrm{~Hz}), 61.51(\mathrm{~s}), 61.35(\mathrm{~s}), 61.21(\mathrm{~s}), 58.28(\mathrm{~d}, J=7.68 \mathrm{~Hz}), 58.09(\mathrm{~d}, J=8.48$ Hz), 42.90 (s), 42.77 (s), 35.82 (s), 35.62 (s), 24.28 (s), 24.22 (s), 20.08 (s), 20.02 (s), 18.07 (s), $18.04(\mathrm{~s}), 13.31(\mathrm{~s}), 13.27(\mathrm{~s}) .{ }^{31} \mathrm{P}$ NMR $\left(\mathrm{CDCl}_{3}\right): \delta 150.38(\mathrm{~s}), 150.27(\mathrm{~s}) . \mathrm{MS}(\mathrm{CI}) \mathrm{m} / \mathrm{z}$ 433.3 $\left(\mathrm{M}^{+}+1,100.00\right)$. HRMS (CI), $\mathrm{M}^{+}$, Found: 432.2408; calcd for $\mathrm{C}_{20} \mathrm{H}_{37} \mathrm{~N}_{2} \mathrm{O}_{6} \mathrm{P}, 432.2389$.

\section{D-1-O-(tert-Butyldiphenylsilyl)-3-(dicyanoethyl phosphothionate)-2,4,5,6-O-tetrakis (methoxymethylene)-myo-inositol (21)}

Di(2-cyanoethyl) diisopropylphosphorodiamidite $(28 \mathrm{mg}, 0.104 \mathrm{mmol})$ was added under an argon atmosphere to a solution of $\mathbf{1 0}(56 \mathrm{mg}, 0.094 \mathrm{mmol})$ and $1 \mathrm{H}$-tetrazole $(0.48 \mathrm{~mL}, 3 \% \mathrm{wt}$ in $\left.\mathrm{CH}_{3} \mathrm{CN}, 0.207 \mathrm{mmol}\right)$ in $1 \mathrm{~mL}$ dry $\mathrm{CH}_{3} \mathrm{CN}$. After stirring at $\mathrm{rt}$ for $2 \mathrm{~h}$, sulfur $(100 \mathrm{mg})$ and $\mathrm{CS}_{2} /$ pyridine $(1.0 \mathrm{~mL}, 1 / 1, \mathrm{v} / \mathrm{v})$ were added. After stirring at $\mathrm{rt}$ for $2 \mathrm{~h}$, the reaction mixture was filtered and the filtrate was washed with brine, dried over $\mathrm{Na}_{2} \mathrm{SO}_{4}$, and concentrated. FC (EtOAc-hexane, 1:3, v:v) gave $68 \mathrm{mg}$ of $\mathbf{2 1}$ as a colorless oil $(0.085 \mathrm{mmol}, 91 \%) .{ }^{1} \mathrm{H}$ NMR $\left(\mathrm{CDCl}_{3}\right): \delta 7.71-7.65(\mathrm{~m}, 4 \mathrm{H}), 7.44-7.34(\mathrm{~m}, 6 \mathrm{H}), 4.97(\mathrm{~d}, J=6.4 \mathrm{~Hz}, 1 \mathrm{H}), 4.92(\mathrm{~d}, J=6.0 \mathrm{~Hz}$, $1 \mathrm{H}), 4.85(\mathrm{~d}, J=6.4 \mathrm{~Hz}, 1 \mathrm{H}), 4.78(\mathrm{~d}, J=7.2 \mathrm{~Hz}, 1 \mathrm{H}), 4.73(\mathrm{~d}, J=6.4 \mathrm{~Hz}, 1 \mathrm{H}), 4.53(\mathrm{~d}, J=$ $6.8 \mathrm{~Hz}, 1 \mathrm{H}), 4.43(\mathrm{~d}, J=6.8 \mathrm{~Hz}, 1 \mathrm{H}), 4.22-3.86(\mathrm{~m}, 8 \mathrm{H}), 3.44-3.34(\mathrm{~m}, 12 \mathrm{H}), 3.23(\mathrm{~s}, 3 \mathrm{H})$, 2.67-2.58 (m, 4H), $1.06(\mathrm{~s}, 9 \mathrm{H}) .{ }^{13} \mathrm{C} \mathrm{NMR}\left(\mathrm{CDCl}_{3}\right): \delta 136.00(\mathrm{~s}), 135.89(\mathrm{~s}), 133.88(\mathrm{~s}), 132.60$ $(\mathrm{s}), 129.89(\mathrm{~s}), 128.16(\mathrm{~s}), 127.82(\mathrm{~s}), 116.39(\mathrm{~s}), 99.19(\mathrm{~s}), 98.86(\mathrm{~s}), 98.45(\mathrm{~s}), 97.71(\mathrm{~s}), 78.91$ (s), $78.76(\mathrm{~s}), 78.16(\mathrm{~d}, J=5.45 \mathrm{~Hz}), 77.88(\mathrm{~s}), 77.24(\mathrm{~d}, J=6.16 \mathrm{~Hz}), 73.52(\mathrm{~s}), 62.37$ (d, $J=$ $3.84 \mathrm{~Hz}$ ), 61.98 (d, $J=3.13 \mathrm{~Hz}), 56.74(\mathrm{~s}), 56.72$ (s), 55.59 (s), 27.15 (s), $19.22(\mathrm{~s}), 19.17$ (s), 19.14 (s), 19.07 (s), 18.98 (s). ${ }^{31} \mathrm{P}$ NMR $\left(\mathrm{CDCl}_{3}\right): \delta 68.69$ (s). MS (CI) $\mathrm{m} / z .797 .3\left(\mathrm{M}^{+}+1\right.$, 43.15). HRMS (CI), $\mathrm{M}^{+}$, Found: 796.2845; calcd for $\mathrm{C}_{36} \mathrm{H}_{53} \mathrm{~N}_{2} \mathrm{O}_{12} \mathrm{PSSi}$, 796.2826.

\section{D-3-(Dicyanoethyl phosphothionate)-2,4,5,6-O-tetrakis(methoxymethylene)-myo-inositol}

(22)

A solution of $35 \mathrm{mg}(0.035 \mathrm{mmol})$ of $\mathbf{2 1}$ in THF $(1 \mathrm{~mL})$ was added along with anhydrous pyridine $(0.4 \mathrm{~mL})$ and hydrogen fluoride pyridine complex $(70 \%, 0.2 \mathrm{~mL})$ at $\mathrm{rt}$ into a Teflon container. After stirring for 3 weeks, the reaction was complete as determined by TLC; the reaction was then diluted with ethyl acetate $(30 \mathrm{~mL})$, and washed with $10 \%$ sodium bicarbonate $(8 \mathrm{~mL} \times 2)$. The organic layer was washed with brine, dried over $\mathrm{Na}_{2} \mathrm{SO}_{4}$, and concentrated. FC (acetone-hexane, 1:3, v:v) gave $21 \mathrm{mg}$ of 22 as a colorless liquid $(0.038 \mathrm{mmol}, 86 \%) .{ }^{1} \mathrm{H}$ NMR $\left(\mathrm{CDCl}_{3}\right): \delta 4.85-4.71(\mathrm{~m}, 8 \mathrm{H}), 4.34(\mathrm{~m}, 5 \mathrm{H}), 4.20(\mathrm{~s}, 1 \mathrm{H}), 4.10(\mathrm{~s}, 1 \mathrm{H}), 4.01(\mathrm{t}, J=10.0$ $\mathrm{Hz}, 1 \mathrm{H}), 3.64(\mathrm{t}, J=10.0 \mathrm{~Hz}, 1 \mathrm{H}), 3.44(\mathrm{~m}, 14 \mathrm{H}), 2.75(\mathrm{~m}, 4 \mathrm{H}) .{ }^{13} \mathrm{C} \mathrm{NMR}\left(\mathrm{CDCl}_{3}\right): \delta 115.48$ (s), 108.75 (s), 97.73 (s), 97.50 (s), 97.14 (s), 82.50 (s), 78.21 (d, J=1.62 Hz), 77.34 (d, $J=$ $6.87 \mathrm{~Hz}), 75.57(\mathrm{~d}, J=6.97 \mathrm{~Hz}), 69.43(\mathrm{~s}), 61.72(\mathrm{~d}, J=3.84 \mathrm{~Hz}), 61.47(\mathrm{~d}, J=3.94 \mathrm{~Hz}), 55.76$ (s), 55.39 (s), 55.12 (s), 54.99 (s), 18.48 (s), 18.45 (s), 18.39 (s), 18.37 (s). ${ }^{31} \mathrm{P}$ NMR $\left(\mathrm{CDCl}_{3}\right): \delta 68.12(\mathrm{~s})$. MS (CI) $m / z 559.2\left(\mathrm{M}^{+}+1,17.87\right)$. HRMS (CI), $\mathrm{M}^{+}$, Found: 558.1686; calcd for $\mathrm{C}_{20} \mathrm{H}_{35} \mathrm{~N}_{2} \mathrm{O}_{12} \mathrm{PS}, 558.1648$. 


\section{D-O-(1,2-Di-O-oleoyl-sn-(2S)-glycerol-3-O-cyanoethylphospho)-3-(dicyanoethyl phosphothionate)-2,4,5,6-O-tetrakis(methoxymethylene)-myo-inositol (23a)}

To a solution of $12 \mathrm{mg}$ of alcohol $22(0.022 \mathrm{mmol})$ in dry THF $(0.5 \mathrm{~mL})$ was added $N, N$ diisopropyl- $O$-cyanoethyl- $O$-(di-oleoyl-s $n$-(2S)-glycerol)phosphonamidite ( $25 \mathrm{mg}, 0.030$ $\mathrm{mmol}$ ) and $1 H$-tetrazole $(6 \mathrm{mg}, 0.26 \mathrm{~mL}, 0.088 \mathrm{mmol})$. The mixture was stirred at $\mathrm{rt}$ for $16 \mathrm{~h}$. Oxidation was then performed with $t$ - BuOOH $(9.9 \mathrm{mg}, 11 \mu \mathrm{L}, 0.110 \mathrm{mmol})$ at $\mathrm{rt}$ for $1 \mathrm{~h}$. The solution was diluted with $\mathrm{CH}_{2} \mathrm{Cl}_{2}(20 \mathrm{~mL})$ and washed with $10 \%$ sodium bisulfite. The organic layer was concentrated and the residue purified by FC (acetone-hexane, 1:3, v:v) to give 25 $\mathrm{mg}$ of 23a as a colorless oil $(0.019 \mathrm{mmol}, 88 \%){ }^{1} \mathrm{H}$ NMR $\left(\mathrm{CDCl}_{3}\right): \delta 5.35(\mathrm{~m}, 4 \mathrm{H}), 5.22(\mathrm{~m}$, $1 \mathrm{H}), 4.83-4.74(\mathrm{~m}, 8 \mathrm{H}), 4.42-4.19(\mathrm{~m}, 12 \mathrm{H}), 4.10(\mathrm{~m}, 2 \mathrm{H}), 3.42(\mathrm{~m}, 12 \mathrm{H}), 2.78(\mathrm{~m}, 6 \mathrm{H}), 2.29$ $(\mathrm{m}, 4 \mathrm{H}), 1.99(\mathrm{~m}, 8 \mathrm{H}), 1.57(\mathrm{~m}, 4 \mathrm{H}), 1.28(\mathrm{~m}, 42 \mathrm{H}), 0.85(\mathrm{t}, J=7.2 \mathrm{~Hz}, 6 \mathrm{H}) .{ }^{13} \mathrm{C} \mathrm{NMR}$ $\left(\mathrm{CDCl}_{3}\right): \delta 173.23(\mathrm{~s}), 172.84(\mathrm{~s}), 172.81(\mathrm{~s}), 130.00(\mathrm{~s}), 129.67(\mathrm{~s}), 116.63(\mathrm{~s}), 116.49(\mathrm{~s})$, $98.91(\mathrm{~s}), 98.93(\mathrm{~s}), 98.55(\mathrm{~s}), 98.49(\mathrm{~s}), 98.01(\mathrm{~s}), 97.96(\mathrm{~s}), 79.17(\mathrm{~s}), 76.40(\mathrm{~m}), 75.70$ (d, $J$ $=19.29 \mathrm{~Hz}), 69.28(\mathrm{~d}, J=5.35 \mathrm{~Hz}), 66.09(\mathrm{~d}, J=5.35 \mathrm{~Hz}), 65.98(\mathrm{~d}, J=5.45 \mathrm{~Hz}), 62.89(\mathrm{~d}$, $J=3.84 \mathrm{~Hz}), 62.70(\mathrm{~m}), 62.30(\mathrm{~d}, J=5.35 \mathrm{~Hz}), 62.24(\mathrm{~d}, J=4.55 \mathrm{~Hz}), 61.60(\mathrm{~s}), 56.64(\mathrm{~s})$, 56.62 (s), 56.59 (s), 56.03 (s), 34.10 (s), 33.94 (s), 31.87 (s), 29.73 (s), 29.70 (s), 29.50 (s), 29.29 (s), 29.21 (s), 29.19 (s), 29.12 (s), 29.08 (s), 29.06 (s), 27.19 (s), 27.16 (s), 24.79 (s), $22.65(\mathrm{~s}), 19.69(\mathrm{~s}), 19.62(\mathrm{~s}), 19.44(\mathrm{~s}), 19.36$ (s), 14.09 (s). ${ }^{31} \mathrm{P}$ NMR $\left(\mathrm{CDCl}_{3}\right): \delta 67.86(\mathrm{~s})$, 67.70 (s), -0.84 (s), -1.25 (s). MS (CI) $m / z 1294.3\left(\mathrm{M}^{+}, 40.74\right), 1262.2\left(\mathrm{M}^{+}-\mathrm{OCH}_{4}, 100.00\right)$. HRMS (CI), $\mathrm{M}^{+}$, Found: 1293.6830 Calcd for $\mathrm{C}_{62} \mathrm{H}_{109} \mathrm{~N}_{3} \mathrm{O}_{19} \mathrm{P}_{2} \mathrm{~S}, 1293.6851$.

\section{D-O-(1,2-Di-O-oleoyl-sn-(2S)-glycerol-3- phospho)-3-(phosphothionate)-myo-inositol, (24a)}

To a solution of $21 \mathrm{mg}$ of compound $23 \mathrm{a}(0.016 \mathrm{mmol})$ in $\mathrm{CH}_{3} \mathrm{CN}(1.0 \mathrm{~mL})$ under $\mathrm{N}_{2}$ was added triethylamine $(0.5 \mathrm{~mL})$ followed by the addition of bistrifluoromethylsilylacetamide $(0.50 \mathrm{~mL})$. After $24 \mathrm{~h}$, the reaction mixture was concentrated and the residue was dissolved in $30 \mathrm{~mL}$ of $8 \mathrm{mM}$ ammonium acetate (pH 7.1). The water phase was lyophilized and white powder was obtained. The anhydrous white powder was dissolved in ethanethiol $(1 \mathrm{~mL})$ and treated with boron trifluoride diethyl etherate $(13 \mu \mathrm{L})$. After $3 \mathrm{~h}$, the reaction was stopped by adding dry triethylamine $(20 \mu \mathrm{L})$. The thiol was removed by evaporation and the semi-solid residue was dissolved in ammonium acetate buffer. $\mathrm{FC}\left(\mathrm{CHCl}_{3}-\mathrm{CH}_{3} \mathrm{OH}-\mathrm{NH}_{4} \mathrm{OH}(2.0 \mathrm{M})\right.$ : 9:7:2, v:v:v) provided $15 \mathrm{mg}$ of pure $24 \mathbf{a}(0.015 \mathrm{mmol}, 93 \%)$. ${ }^{1} \mathrm{H}$ NMR $\left(\mathrm{CDCl}_{3}-\mathrm{CD}_{3} \mathrm{OD}, 3: 2\right.$, v:v): $\delta 5.32(\mathrm{~m}, 4 \mathrm{H}), 5.24(\mathrm{~m}, 1 \mathrm{H}), 4.20(\mathrm{~m}, 3 \mathrm{H}), 4.04-3.95(\mathrm{~m}, 5 \mathrm{H}), 3.77(\mathrm{~m}, 2 \mathrm{H}), 3.20(\mathrm{~m}$, 2H), $2.29(\mathrm{~m}, 4 \mathrm{H}), 2.00(\mathrm{~m}, 8 \mathrm{H}), 1.57(\mathrm{~m}, 4 \mathrm{H}), 1.27(\mathrm{~m}, 42 \mathrm{H}), 0.86(\mathrm{t}, J=7.2 \mathrm{~Hz}, 6 \mathrm{H}) .{ }^{13} \mathrm{C}$ NMR $\left(\mathrm{CDCl}_{3}-\mathrm{CD}_{3} \mathrm{OD}, 3: 2, \mathrm{v}: \mathrm{v}\right): \delta 175.15(\mathrm{~s}), 174.88(\mathrm{~s}), 130.71(\mathrm{~s}), 130.43(\mathrm{~s}), 76.82(\mathrm{~s})$, $75.73(\mathrm{~s}), 75.13(\mathrm{~s}), 72.63(\mathrm{~s}), 72.27(\mathrm{~s}), 71.61(\mathrm{~s}), 71.42(\mathrm{~s}), 64.53(\mathrm{~s}), 63.86(\mathrm{~s}), 34.95(\mathrm{~s})$, 34.83 (s), 32.60 (s), 30.50 (s), 30.47 (s), 30.44 (s), 30.19 (s), 30.06 (s), 30.00 (s), 29.97 (s), $29.90(\mathrm{~s}), 29.87(\mathrm{~s}), 29.82(\mathrm{~s}), 27.91(\mathrm{~s}), 27.88(\mathrm{~s}), 25.67(\mathrm{~s}), 25.57$ (s), 23.35 (s), 14.58 (s). ${ }^{31} \mathrm{P}$ NMR $\left(\mathrm{CDCl}_{3}-\mathrm{CD}_{3} \mathrm{OD}, 3: 2\right.$, v:v): $\delta 48.96$ (s), 0.74 (s). MS (ESI) $\mathrm{m} / \mathrm{z} 981.64\left(\mathrm{M}^{+}-\right.$ $\mathrm{NH}_{4}^{+}, 100.00$ ). HRMS (MALDI), $\mathrm{M}^{+}+2 \mathrm{NH}_{4}{ }^{+}+\mathrm{H}^{+}$, Found: 1046.6530; Calcd for $\mathrm{C}_{45} \mathrm{H}_{102} \mathrm{NO}_{15} \mathrm{P} 2 \mathrm{~S}, 1046.6568$.

\section{D-O-(1,2-Di-O-pamitoyl-sn-(2S)-glycerol-3-O-cyanoethylphospho)-3-(dicyanoethyl phosphothionate)-2,4,5,6-O-tetrakis(methoxymethylene)-myo-inositol (23b)}

To a solution of alcohol $22(53 \mathrm{mg}, 0.095 \mathrm{mmol})$ in dry THF $(0.5 \mathrm{~mL})$, was added $N, N$ diisopropyl- $O$-cyanoethyl- $O$-(di-palmitoyl-sn-( $2 S$ )-glycerol)phosphonamidite (102 mg, 0.133 $\mathrm{mmol})$ and $1 \mathrm{H}$-tetrazole $(1.12 \mathrm{~mL}, 3 \% \mathrm{wt}, 0.380 \mathrm{mmol})$. The mixture was stirred at $\mathrm{rt}$ for 16 hour. Then oxidation was performed with $t$-BuOOH $(60 \mu \mathrm{L}, 0.380 \mathrm{mmol})$ at $\mathrm{rt}$ for $1 \mathrm{~h}$. The solution was diluted with methylene chloride $(20 \mathrm{~mL})$ and washed with $10 \%$ sodium bisulfite. The organic layer was concentrated and the residue was purified by FC (acetone-hexane, 1:3, v:v) to give $95 \mathrm{mg}$ of pure product $(0.077 \mathrm{mmol}, 81 \%)$ as colorless oil. ${ }^{1} \mathrm{H} \mathrm{NMR}\left(\mathrm{CDCl}_{3}\right): \delta$ $5.24(\mathrm{~m}, 1 \mathrm{H}), 4.83-4.72(\mathrm{~m}, 7 \mathrm{H}), 4.39(\mathrm{~m}, 1 \mathrm{H}), 4.31-4.13(\mathrm{~m}, 12 \mathrm{H}), 3.93(\mathrm{~m}, 2 \mathrm{H}), 3.44(\mathrm{~m}$, 
2H), $3.40(\mathrm{~m}, 12 \mathrm{H}), 2.77(\mathrm{~m}, 6 \mathrm{H}), 2.28(\mathrm{~m}, 4 \mathrm{H}), 1.56(\mathrm{~m}, 4 \mathrm{H}), 1.21(\mathrm{~m}, 48 \mathrm{H}), 0.84(\mathrm{t}, J=7.2$ $\mathrm{Hz}, 6 \mathrm{H}) .{ }^{13} \mathrm{C} \mathrm{NMR}\left(\mathrm{CDCl}_{3}\right): \delta 173.23(\mathrm{~s}), 172.84(\mathrm{~s}), 116.61(\mathrm{~s}), 116.48(\mathrm{~s}), 98.87(\mathrm{~s}), 98.51$ (s), $98.45(\mathrm{~s}), 97.97(\mathrm{~s}), 97.92(\mathrm{~s}), 79.14(\mathrm{~s}), 76.34(\mathrm{~m}), 75.77(\mathrm{~s}), 75.56(\mathrm{~s}), 69.29(\mathrm{~s}), 66.11$ $(\mathrm{m}), 62.71(\mathrm{~d}, J=3.84 \mathrm{~Hz}), 62.20(\mathrm{~d}, J=12.32 \mathrm{~Hz}), 61.60(\mathrm{~s}), 58.31(\mathrm{~s}), 56.80(\mathrm{~s}), 56.55(\mathrm{~s})$, $55.99(\mathrm{~s}), 34.09(\mathrm{~s}), 33.94(\mathrm{~s}), 31.86(\mathrm{~s}), 29.64(\mathrm{~s}), 29.60(\mathrm{~s}), 29.45(\mathrm{~s}), 29.30(\mathrm{~s}), 29.26(\mathrm{~s})$, $29.08(\mathrm{~s}), 29.06(\mathrm{~s}), 24.78(\mathrm{~s}), 22.63(\mathrm{~s}), 19.66(\mathrm{~s}), 19.58(\mathrm{~s}), 19.40(\mathrm{~s}), 19.32(\mathrm{~s}), 14.06$ (s). ${ }^{31} \mathrm{P}$ NMR $\left(\mathrm{CDCl}_{3}\right): \delta 67.84(\mathrm{~s}), 67.68(\mathrm{~s}),-0.88(\mathrm{~s}),-1.28(\mathrm{~s})$. MS (ESI) $\mathrm{m} / z 1242.8$ $\left(\mathrm{M}^{+}+1,18.00\right)$. HRMS (MALDI), $\mathrm{M}^{+}+\mathrm{Na}$, Found: 1264.6463 Calcd for $\mathrm{C}_{58} \mathrm{H}_{105} \mathrm{~N}_{3} \mathrm{NaO}_{19} \mathrm{P}_{2} \mathrm{~S}, 1264.6436$.

\section{D-O-(1,2-Di-O-palmitoyl-sn-(2S)-glycerol-3-phospho)-3-(phosphothionate)-myo-inositol (24b)}

To a solution of $35 \mathrm{mg}$ of compound $\mathbf{2 3 b}(0.028 \mathrm{mmol})$ in $\mathrm{CH}_{3} \mathrm{CN}(1.0 \mathrm{~mL})$ under $\mathrm{N}_{2}$ was added triethylamine $(0.5 \mathrm{~mL})$ followed by the addition of bistrifluoromethylsilylacetamide $(0.50 \mathrm{~mL})$. After $24 \mathrm{~h}$, the reaction mixture was concentrated and the residue was dissolved in $30 \mathrm{~mL}$ of $8 \mathrm{mM}$ ammonium acetate $(\mathrm{pH} 7.1)$. The water phase was lyophilized and white powder was obtained. The anhydrous white powder was dissolved in ethanethiol $(2 \mathrm{~mL})$ and treated with boron trifluoride diethyl etherate $(14 \mu \mathrm{L})$. After $3 \mathrm{~h}$, the reaction was stopped by adding dry triethylamine $(30 \mu \mathrm{L})$. The thiol was removed by evaporation and the semi-solid residue was dissolved in ammonium acetate buffer. $\mathrm{FC}\left(\mathrm{CHCl}_{3}-\mathrm{CH}_{3} \mathrm{OH}-\mathrm{NH}_{4} \mathrm{OH}(2.0 \mathrm{M}): 9: 7: 2\right.$, v:v:v) provided $22 \mathrm{mg}$ of pure $24 \mathbf{b}(0.022 \mathrm{mmol}, 79 \%) .{ }^{1} \mathrm{H} \mathrm{NMR}\left(\mathrm{CDCl}_{3}-\mathrm{CD}_{3} \mathrm{OD}, 3: 2, \mathrm{v}: \mathrm{v}\right): \delta 5.27$ (m, 1H), $3.93(\mathrm{dd}, J=12.0,3.6 \mathrm{~Hz}, 1 \mathrm{H}), 3.82(\mathrm{~m}, 2 \mathrm{H}), 3.73-3.60(\mathrm{~m}, 5 \mathrm{H}), 3.30(\mathrm{~m}, 2 \mathrm{H}), 2.33$ (m, 4H), $1.62(\mathrm{~m}, 4 \mathrm{H}), 1.56$ (dd, $J=17.6,6.8 \mathrm{~Hz}, 3 \mathrm{H}), 1.27(\mathrm{~m}, 48 \mathrm{H}), 0.84(\mathrm{t}, J=7.2 \mathrm{~Hz}$, 6H). ${ }^{31} \mathrm{P}$ NMR $\left(\mathrm{CDCl}_{3}-\mathrm{CD}_{3} \mathrm{OD}, 3: 2\right.$, v:v): $\delta 48.96$ (s), 0.74 (s). MS (ESI) $\mathrm{m} / z .281 .64\left(\mathrm{M}^{+}+\right.$ $\mathrm{Na}, 17.00$ ). HRMS (MALDI), $\mathrm{M}^{+}+\mathrm{Na}^{+}$, Found: 980.5410; Calcd for $\mathrm{C}_{41} \mathrm{H}_{89} \mathrm{~N}_{3} \mathrm{NaO}_{15} \mathrm{P}_{2} \mathrm{~S}$, 980.5387.

\section{D-O-(1,2-Di-O-butanoyl-sn-(2S)-glycerol-3-O-cyanoethylphospho)-3-(dicyanoethyl phosphothionate)-2,4,5,6-O-tetrakis(methoxymethylene)-myo-inositol (23c)}

To a solution of alcohol $22(35 \mathrm{mg}, 0.063 \mathrm{mmol})$ in dry THF $(0.5 \mathrm{~mL})$ was added $N, N$ diisopropyl- $O$-cyanoethyl- $O$-(di-butanoyl-sn-(2S)-glycerol)phosphonamidite (38 mg, 0.088 $\mathrm{mmol})$ and $1 \mathrm{H}$-tetrazole $(0.74 \mathrm{~mL}, 3 \% \mathrm{wt}, 0.252 \mathrm{mmol})$. The mixture was stirred at $\mathrm{rt}$ for 16 $\mathrm{h}$. Then oxidation was performed with $t$ - BuOOH $(33 \mu \mathrm{L}, 0.300 \mathrm{mmol})$ at $\mathrm{rt}$ for $1 \mathrm{~h}$. The solution was diluted with $\mathrm{CH}_{2} \mathrm{Cl}_{2}(20 \mathrm{~mL})$ and washed with $10 \%$ sodium bisulfite. The organic layer was concentrated and the residue was chromatographed (acetone-hexane, 1:3, v:v) on silica gel to give pure product as a colorless oil $(49 \mathrm{mg}, 0.054 \mathrm{mmol}, 86 \%) .{ }^{1} \mathrm{H} \mathrm{NMR}\left(\mathrm{CDCl}_{3}\right): \delta$ $5.26(\mathrm{~m}, 1 \mathrm{H}), 4.83-4.74(\mathrm{~m}, 9 \mathrm{H}), 4.40(\mathrm{~d}, J=2.4 \mathrm{~Hz}, 1 \mathrm{H}), 4.35-4.12(\mathrm{~m}, 12 \mathrm{H}), 3.79(\mathrm{~m}, 2 \mathrm{H})$, 3.45-3.38 (m, 12H), $2.76(\mathrm{~m}, 6 \mathrm{H}), 2.31(\mathrm{~m}, 4 \mathrm{H}), 1.67(\mathrm{~m}, 4 \mathrm{H}), 0.95(\mathrm{t}, J=7.2 \mathrm{~Hz}, 3 \mathrm{H}), 0.91$ $(\mathrm{t}, J=7.2 \mathrm{~Hz}, 3 \mathrm{H}) .{ }^{13} \mathrm{C}$ NMR $\left(\mathrm{CDCl}_{3}\right): \delta 173.07(\mathrm{~s}), 172.68(\mathrm{~s}), 116.63(\mathrm{~s}), 116.50(\mathrm{~s}), 98.91$ (s), 98.89 (s), 98.48 (s), $98.00(\mathrm{~s}), 97.94(\mathrm{~s}), 79.16(\mathrm{~m}), 76.41(\mathrm{~m}), 75.69(\mathrm{~d}, J=19.91 \mathrm{~Hz})$, $69.27(\mathrm{~d}, J=6.13 \mathrm{~Hz}), 66.14(\mathrm{dd}, J=12.97,7.64 \mathrm{~Hz}), 62.90(\mathrm{~d}, J=3.82 \mathrm{~Hz}), 62.70(\mathrm{~s}), 62.38$ (d, $J=4.63 \mathrm{~Hz}), 62.22(\mathrm{~d}, J=4.20 \mathrm{~Hz}), 61.53(\mathrm{~s}), 56.84(\mathrm{~s}), 56.61(\mathrm{~s}), 56.02(\mathrm{~s}), 35.94(\mathrm{~s})$, $35.80(\mathrm{~s}), 19.68 \mathrm{9s}), 19.61(\mathrm{~s}), 19.43(\mathrm{~s}), 19.35(\mathrm{~s}), 18.27(\mathrm{~s}), 13.58(\mathrm{~s}), 13.54(\mathrm{~s}) .{ }^{31} \mathrm{P}$ NMR $\left(\mathrm{CDCl}_{3}\right): \delta 67.83(\mathrm{~s}), 67.70(\mathrm{~s}),-0.90(\mathrm{~s}),-1.30(\mathrm{~s})$. MS (ESI) $\mathrm{m} / \mathrm{z} 906.41\left(\mathrm{M}^{+}+1,30.00\right)$. HRMS (MALDI), $\mathrm{M}^{+}+\mathrm{Na}+\mathrm{NH}_{4}{ }^{+}$, Found: 946.2996 ; calcd for $\mathrm{C}_{34} \mathrm{H}_{61} \mathrm{~N}_{4} \mathrm{NaO}_{19} \mathrm{P}_{2} \mathrm{~S}, 946.3024$.

1D-O-(1,2-Di-O-butanoyl-sn-(2S)-glycerol-3-phospho)-3-(phosphothionate)-myo-inositol (24c)

To a solution of $20 \mathrm{mg}$ of compound 23a $(0.022 \mathrm{mmol})$ in $\mathrm{CH}_{3} \mathrm{CN}(1.0 \mathrm{~mL})$ under $\mathrm{N}_{2}$ was added triethylamine $(0.5 \mathrm{~mL})$ followed by the addition of bistrifluoromethylsilylacetamide $(0.50 \mathrm{~mL})$. After $24 \mathrm{~h}$, the reaction mixture was concentrated and the residue was dissolved in 
$30 \mathrm{~mL}$ of $8 \mathrm{mM}$ ammonium acetate $(\mathrm{pH} 7.1)$. The water phase was lyophilized and white powder was obtained. The anhydrous white powder was dissolved in ethanethiol $(1 \mathrm{~mL})$ and treated with boron trifluoride diethyl etherate $(11 \mu \mathrm{L})$. After $3 \mathrm{~h}$, the reaction was stopped by adding dry triethylamine $(20 \mu \mathrm{L})$. The thiol was removed by evaporation and the semi-solid residue was dissolved in ammonium acetate buffer. $\mathrm{FC}\left(\mathrm{CHCl}_{3}-\mathrm{CH}_{3} \mathrm{OH}-\mathrm{NH}_{4} \mathrm{OH}(2.0 \mathrm{M})\right.$ : 9:7:2, v:v:v) provided $11 \mathrm{mg}$ of pure $\mathbf{2 4 c}(0.018 \mathrm{mmol}, 80 \%) .{ }^{1} \mathrm{H}$ NMR $\left(\mathrm{CDCl}_{3}-\mathrm{CD}_{3} \mathrm{OD}, 3: 2, \mathrm{v}: \mathrm{v}\right): \delta 5.26$ $(\mathrm{m}, 1 \mathrm{H}), 3.93(\mathrm{~m}, 2 \mathrm{H}), 3.82(\mathrm{~m}, 2 \mathrm{H}), 3.73-3.60(\mathrm{~m}, 5 \mathrm{H}), 3.30(\mathrm{~m}, 2 \mathrm{H}), 2.31(\mathrm{~m}, 4 \mathrm{H}), 1.67(\mathrm{~m}$, $4 \mathrm{H}), 0.95(\mathrm{t}, J=7.2 \mathrm{~Hz}, 3 \mathrm{H}), 0.91(\mathrm{t}, J=7.2 \mathrm{~Hz}, 3 \mathrm{H}) .{ }^{31} \mathrm{P} \mathrm{NMR}\left(\mathrm{CDCl}_{3}-\mathrm{CD}_{3} \mathrm{OD}, 3: 2\right.$, v:v): $\delta$ 48.96 (s), 0.74 (s). MS (ESI) $m / z 624.27\left(\mathrm{M}^{+}+3,21.00\right), 667.28\left(\mathrm{M}^{+}+2+2 \mathrm{Na}^{+}, 100.00\right)$. HRMS (MALDI), $\mathrm{M}^{+}+\mathrm{Na}^{+}$, Found: 644.1652; Calcd for $\mathrm{C}_{17} \mathrm{H}_{41} \mathrm{~N}_{3} \mathrm{O}_{15} \mathrm{P}_{2} \mathrm{~S}, 644.1631$.

\section{Protein Expression and Purification}

DNA fragments encoding residues 1325-1410 of human EEA1 FYVE and residues 2-122 of yeast Vam7 PX were cloned in pGEX-KG and pGEX-2T vectors (Amersham). The ${ }^{15} \mathrm{~N}$ labeled proteins were expressed in E. coli BL21 (DE3) pLysS and BL21 Codon Plus RP strains in minimal media supplemented with ${ }^{15} \mathrm{NH}_{4} \mathrm{Cl}$ (Cambridge Isotope). Bacteria were harvested by centrifugation after induction with IPTG $(0.5 \mathrm{mM})$ and lysed by French press. The glutathione S-transferase (GST)-fusion FYVE and PX were purified on a glutathione sepharose 4B column (Amersham). The GST tag was cleaved with thrombin (Sigma). The proteins were further purified by FPLC and concentrated in Millipore concentrators (Millipore). The buffers

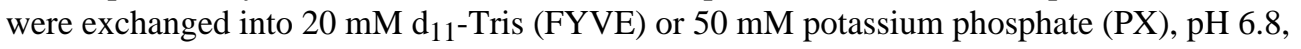
100-200 mM KCl, 1-20 mM perdeuterated dithiothreitol, $50 \mu \mathrm{M}$ 4-amidinophenylmethane sulfonyl fluoride, $1 \mathrm{mM} \mathrm{NaN}_{3}$, and $7 \%{ }^{2} \mathrm{H}_{2} \mathrm{O}$.

\section{NMR spectroscopy and titration of Ptdlns(3)P analogs}

NMR spectra were recorded at $25^{\circ} \mathrm{C}$ on Varian INOVA $500 \mathrm{MHz}$ spectrometer. The ${ }^{1} \mathrm{H}_{-}{ }^{15} \mathrm{~N}$ heteronuclear single quantum coherence (HSQC) spectra of $0.2-0.3 \mathrm{mM}$ uniformly ${ }^{15} \mathrm{~N}$ labeled FYVE and PX domains were collected while dibutanoyl $\left(\mathrm{C}_{4}\right)$ - or dipalmitoyl $\left(\mathrm{C}_{16}\right)$ PtdIns(3)P analogs (Echelon Biosciences) (up to $4 \mathrm{mM}$ ) embedded in micelles consisting of $\mathrm{d}_{38}$-DPC (250 mM) (Cambridge Isotopes) or DHPC/CHAPS (100 mM/17 mM) (Avanti/ Anatrace) were added stepwise.

\section{Phosphorylation of Ptdlns(3)P analogues by PIKfyve}

Phosphatase-resistant dipalmitoyl and dioleoyl analogues of PtdIns(3)P and di-C $\mathrm{C}_{16}$ PtdIns 3$\mathrm{P}$ (Echelon Biosciences, Inc.) were separately prepared as $0.5 \mathrm{mM}$ aqueous stocks and stored at $-80^{\circ} \mathrm{C}$. Just before use as substrates in the phosphorylation reaction with PIKfyve immunoprecipitates, a $60 \mu 1$ aliquot of the PtdIns(3)P, the stabilized analogues, or soybean PtdIns (Avanti Polar Lipids, Inc.) were evaporated down to dryness with absolute ethanol (2 $\times 200 \mu \mathrm{l}$ ) under a stream of dry $\mathrm{N}_{2}$. Lipids were then reconstituted in an equal volume of lipid buffer $(20 \mathrm{mM} \mathrm{pH}, 7.5$, HEPES, $1 \mathrm{mM}$ EDTA) by sonication $(2 \times 30 \mathrm{~s})$ in a bath sonicator at room temperature. A $10 \mu \mathrm{l}$ aliquot of each $0.5 \mathrm{mM}$ phosphoinositide reconstituted in lipid buffer was then phosphorylated with immunoprecipitates of PIKfyve immune (R7069) or preimmune sera derived from PC-12 cell lysates prepared in RIPA buffer $(50 \mathrm{mM}$ Tris-HCl, $\mathrm{pH} 8.0,150 \mathrm{mM} \mathrm{NaCl}, 1 \% \mathrm{w} / \mathrm{v}$ Nonidet P-40, $0.5 \% \mathrm{w} / \mathrm{v}$ sodium deoxycholate) plus protease inhibitors ( $1 \mathrm{mM}$ phenylmethylsulfonyl fluoride, $5 \mu \mathrm{g} / \mathrm{ml}$ leupeptin, $5 \mu \mathrm{g} / \mathrm{ml}$ aprotinin, $1 \mu \mathrm{g} / \mathrm{ml}$ pepstatin and $1 \mathrm{mM}$ benzamidine) and immunoadsorbed onto $10 \mu \mathrm{l}$ of packed protein Asepharose beads, as previously described. ${ }^{61}$ The reaction in $50 \mu$ of assay buffer $(50 \mathrm{mM}, \mathrm{pH}$ 7.5, Tris- $\mathrm{HCl} / 2.5 \mathrm{mM} \mathrm{MnCl} 2 / 2.5 \mathrm{mM} \mathrm{MgCl} 2)$ containing $10 \mu \mathrm{Ci}$ of $\left[\gamma_{-}{ }^{32} \mathrm{P}\right] \mathrm{ATP}(50 \mu \mathrm{M})$ was incubated for $15 \mathrm{~min}$ at $37^{\circ} \mathrm{C}$ before stopping with $200 \mu \mathrm{l}$ of $1 \mathrm{~N} \mathrm{HCl}$ and extracting with 160 $\mu \mathrm{l}$ of 1:1 (v/v) $\mathrm{CHCl}_{3}-\mathrm{CH}_{3} \mathrm{OH}$. The lower chloroform layer containing the ${ }^{32} \mathrm{P}$-labeled lipid product was collected by centrifuging for $30 \mathrm{sec}$ at $5000 \mathrm{rpm}$ in a microfuge and quickly rinsed 
twice with $100 \mu \mathrm{l}$ of $1: 1(\mathrm{v} / \mathrm{v}) 1 \mathrm{~N} \mathrm{HCl}-\mathrm{CH}_{3} \mathrm{OH}$ before spotting $50 \mu \mathrm{l}$ onto a silica-gel glass TLC plate $(20 \times 20$-cm $\times 0.25 \mathrm{~mm}$ layer thickness, Merck) and developing up to the top (4-5 hrs) at room temperature with $65: 35(\mathrm{v} / \mathrm{v}) n$-propanol-2 M acetic acid. Following exposure with X-omat autoradiography film for appropriate length of time the radiolabeled spots were scraped into glass scintillation vials and deacylated by methylaminolysis at $54{ }^{\circ} \mathrm{C}$ for $50 \mathrm{~min}$ by standard protocol. ${ }^{61}$ Recovery of the aqueously soluble deacylation products were then analyzed by HPLC on a Whatman 5- $\mu \mathrm{m}$ Partisphere SAX $\left(\mathrm{H}_{2} \mathrm{PO}_{4}{ }^{-}\right)$column as formerly described 61 and the ${ }^{32} \mathrm{P}$ detected with a Radiomatic 525TR online flow scintillation analyzer and FLO-ONE radiochromatography software (Packard Instrument Co., Downers Grove, IL) by Cerenkov emission in the low-energy tritium channel.

\section{Supplementary Material}

Refer to Web version on PubMed Central for supplementary material.

\section{Acknowledgements}

We thank the NIH (NS29632), the American Cancer Society RSG0513601 (TGK), and the American Diabetes Association and NIH (DK58058) (AS) for financial support of this work.

\section{References}

1. Feng, L.; Ferguson, CG.; Neilsen, PO.; Chakravarty, L.; Rzepecki, P.; Prestwich, GD. Functional Lipidomics. Feng, L.; Prestwich, GD., editors. Dekker-CRC Press; New York: 2005. p. 189-210.

2. Prestwich GD. Chem Biol 2004;11:619-637. [PubMed: 15157873]

3. Vanhaesebroeck B, Leevers SJ, Ahmadi K, Timms J, Katso R, Driscoll PC, Woscholski R, Parker PJ, Waterfield MD. Annu Rev Biochem 2001;70:535-602. [PubMed: 11395417]

4. Yin HL, Janmey PA. Annual Review of Physiology 2003;65:761-789.

5. Wymann MP, Bjorklof K, Calvez R, Finan P, Thomas M, Trifilieff A, Barbier M, Altruda F, Hirsch E, Laffargue M. Biochem Soc Trans 2003;31:275-280. [PubMed: 12546701]

6. Anderson KE, Jackson SP. International Journal of Biochemistry \& Cell Biology 2003;35:1028-1033. [PubMed: 12672472]

7. Drees BE, Mills GB, Rommel C, Prestwich GD. Expert Opin Therapeut Pat 2004;14:703-732.

8. Wetzker R, Rommel C. Curr Pharmaceut Design 2004;10:1915-1922.

9. Wymann MP, Zvelebil M, Laffargue M. Trends in Pharmacological Sciences 2003;24:366-376. [PubMed: 12871670]

10. Jackson SP, Yap C, Anderson K. Biochem Soc Trans 2004;32:387-392. [PubMed: 15046614]

11. Workman P. Biochem Soc Trans 2004;32:393-396. [PubMed: 15046615]

12. Ikonomov OC, Sbrissa D, Fligger J, Foti M, Carpentier JL, Shisheva A. Mol Biol Cell 14;45814591:2003.

13. Kutateladze T, Ogburn K, Watson W, de Beer T, Emr S, Burd C, Overduin M. Molec Cell 1999;3:805811. [PubMed: 10394369]

14. Gaullier JM, Simonsen A, D’Arrigo A, Bremnes B, Stenmark H, Aasland R. Nature 1998;394:432433. [PubMed: 9697764]

15. Gillooly DJ, Simonsen A, Stenmark H. J Cell Biol 2001;155:15-17. [PubMed: 11581282]

16. Petiot A, Faure J, Stenmark H, Gruenberg J. J Cell Biol 2003;162:971-979. [PubMed: 12975344]

17. Sato T, Overduin M, Emr SD. Science 2001;294:1881-1885. [PubMed: 11729306]

18. Wishart MJ, Dixon JE. Trends Cell Biol 2002;12:579-585. [PubMed: 12495846]

19. Laporte J, Bedez F, Bolino A, Mandel JL. Human Molecular Genetics 2003;12:R285-R292. [PubMed: 12925573]

20. Vergne I, Chua J, Lee HH, Lucas M, Belisle J, Deretic V. Proc Natl Acad Sci USA 2005;202:40334038. [PubMed: 15753315]

21. Xu Y, Qian L, Prestwich GD. J Org Chem 2003;68:5320-5330. [PubMed: 12816494] 
22. Xu Y, Qian L, Prestwich GD. Organic Lett 2003;5:2267-2270.

23. Qian L, Xu Y, Hasegawa Y, Aoki J, Mills GB, Prestwich GD. J Med Chem 2003;46:5575-5578. [PubMed: 14667211]

24. Prestwich GD, Xu Y, Qian L, Gajewiak J, Jiang G. Biochem Soc Trans 2005;33:1357-1361. [PubMed: 16246118]

25. Schmitt L, Spiess B, Schlewer G. Tetrahedron Lett 1993;34:7059-7060.

26. Chen J, Profit AA, Prestwich GD. J Org Chem 1996;61:6305-6312. [PubMed: 11667472]

27. Chen J, Feng L, Prestwich GD. J Org Chem 1998;63:6511-6522.

28. Chen J, Prestwich GD. J Org Chem 1998;63:430-431. [PubMed: 11672027]

29. Peng J, Prestwich GD. Tetrahedron Lett 1998;39:3965-3968.

30. Thum O, Chen J, Prestwich GD. Tetrahedron Lett 1996;37:9017-9020.

31. Qiao L, Hu Y, Nan F, Powis G, Kozikowski AP. Org Lett 2000;2:115-117. [PubMed: 10814260]

32. Reddy KK, Saady M, Falck JR. J Org Chem 1995;60:3385-3390.

33. Reddy KK, Ye J, Falck JR, Capdevila JH. Bioorg Med Chem Lett 1997;7:2115-2116.

34. Reddy KK, Rizo J, Falck JR. Tetrahedron Lett 1997;38:4729-4730.

35. Sculimbrene BR, Xu Y, Miller SJ. J Am Chem Soc 2004;126:13182-13183. [PubMed: 15479046]

36. Sculimbrene BR, Miller SJ. J Am Chem Soc 2001;123:10125-10126. [PubMed: 11592903]

37. Gou DM, Chen CS. J Chem Soc, Chem Commun 1994;18:2125-2126.

38. Wang DS, Chen CS. J Org Chem 1996;61:5905-5910.

39. Bruzik KS, Tsai MD. J Am Chem Soc 1992;114:6361-6374.

40. Kubiak RJ, Bruzik KS. J Org Chem 2002:960-968.

41. Prestwich GD. Acc Chem Res 1996;29:503-513.

42. Denmark SE, Chen CT. J Org Chem 1994;59:2922-2924.

43. Malachowski WP, Coward JK. J Org Chem 1994;59:7625-7634.

44. Esalthazor M, Flores RA. J Org Chem 1980;45:529-531.

45. Lal GS, Pez GP, Syvret RG. Chem Rev 1996;96:1737-1755. [PubMed: 11848809]

46. Jeanmarie T, Hervaud Y, Boutevin B. Phosphorous, Sulfur and Silicon 2002;177:1137-1145.

47. Hamilton CJ, Roberts SM. J Chem Soc, Perkin Trans 1;1999:1051-1056.

48. Deussen HJ, Danielsen S, Breinholt J, Borchert TV. Bioorg Med Chem 2000;8:507-513. [PubMed: 10732966]

49. Hirschmann R, Yager KM, Taylor CM, Witherington J, Sprengeler PA, Phillips BW, Moore W, Smith ABI. J Am Chem Soc 1997;119:8177-8190.

50. Borecka B, Chojnowski J, Cypryk M, Michalski J, Zielinska J. J Organomet Chem 1979;171:17-34. 51. Piettre SR, Raboisson P. Tetrahedron Lett 1996;37:2229-2232.

52. Heeb NV, Nambiar KP. Tetrahedron Lett 1993;39:6193-6196.

53. Kurosu M, Marcin LR, Grinsteiner TJ, Kishi Y. J Am Chem Soc 1998;120:6627-6628.

54. Uhlman E, Engels J. Tetrahedron Lett 1986;27:1023-1026.

55. Salamonczyk GM. Tetrahedron Lett 2003;44:7449-7453.

56. Sekine M, Tsuruoka H, Iimura S, Kusuoku H, Wada T. J Org Chem 1996;61:4087-4100. [PubMed: 11667287]

57. Kubiak RJ, Bruzik KS. Bioorg \& Med Chem Lett 1997;7:1231-1234.

58. Auger KR, Carpenterg CL, Cantley LC, Varticovski L. J Biol Chem 1989;264:20181-20184. [PubMed: 2555343]

59. Kutateladze T, Overduin M. Science 2001;291:1793-1796. [PubMed: 11230696]

60. Tollas KF, Rameh LE, Ishihara H, Shibashi Y, Chen J, Prestwich GD, Cantley LC, Carpenter CL. J Biol Chem 1998;273:18040-18046. [PubMed: 9660759]

61. Sbrissa D, Ikonomov OC, Shisheva A. J Biol Chem 1999;274:21589-21597. [PubMed: 10419465] 62. Shisheva A. Cell Biology International 2001;25:1201-1206. [PubMed: 11748912]

63. Sbrissa D, Ikonomov OC, Shisheva A. J Biol Chem 2002;277:6073-6079. [PubMed: 11706043]

$J$ Am Chem Soc. Author manuscript; available in PMC 2008 September 14. 

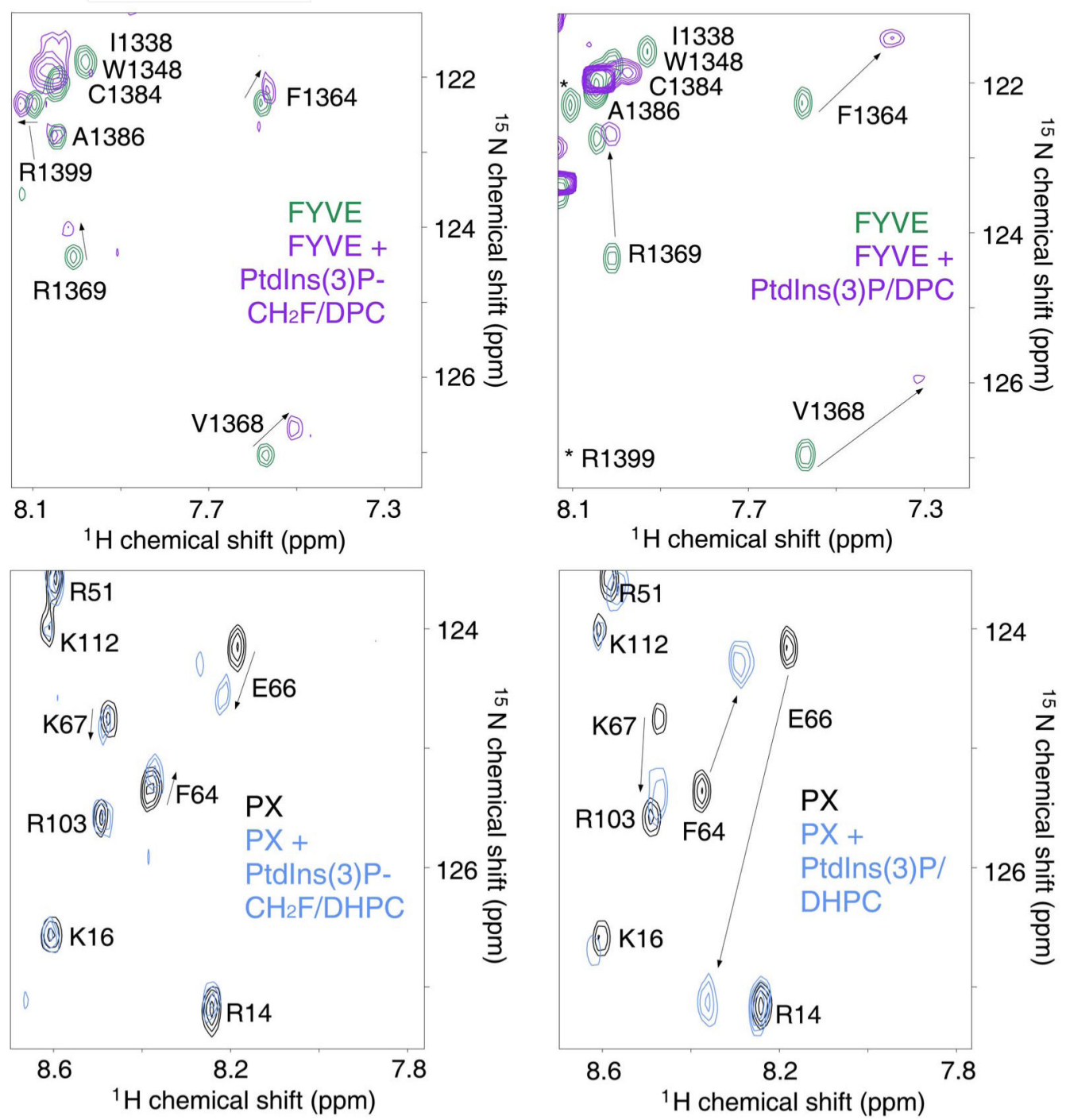

Figure 1.

PtdIns(3)P analogs are recognized by the FYVE and PX domains. Superimposed ${ }^{1} \mathrm{H}_{-}{ }^{15} \mathrm{~N}$ HSQC NMR spectra of (A, B, upper left and right) 0.2 mM EEA1 FYVE domain and (C,D, lower left and right) $0.2 \mathrm{mM}$ Vam7 PX domain collected before and after addition of (A) 4 $\mathrm{mM} \mathrm{C}_{16}$-PtdIns(3)P-CH $\mathrm{CH}_{2} \mathrm{~F} \mathbf{1 6 b}$ and $250 \mathrm{mM} \mathrm{d}_{38}$-DPC; (B) $1 \mathrm{mM} \mathrm{C}_{4}$-PtdIns(3)P and $250 \mathrm{mM}$ $\mathrm{d}_{38}$-DPC; (C) $2 \mathrm{mM} \mathrm{C}_{4}$-PtdIns(3)P-CH $\mathrm{CH}_{2} \mathrm{~F}$ 16c in $100 \mathrm{mM}$ DHPC and 33 mM CHAPS; (D) 2 $\mathrm{mM} \mathrm{C}_{4}$-PtdIns(3)P in $100 \mathrm{mM}$ DHPC and $33 \mathrm{mM}$ CHAPS. Directions of the chemical shift changes are indicated by arrows. 

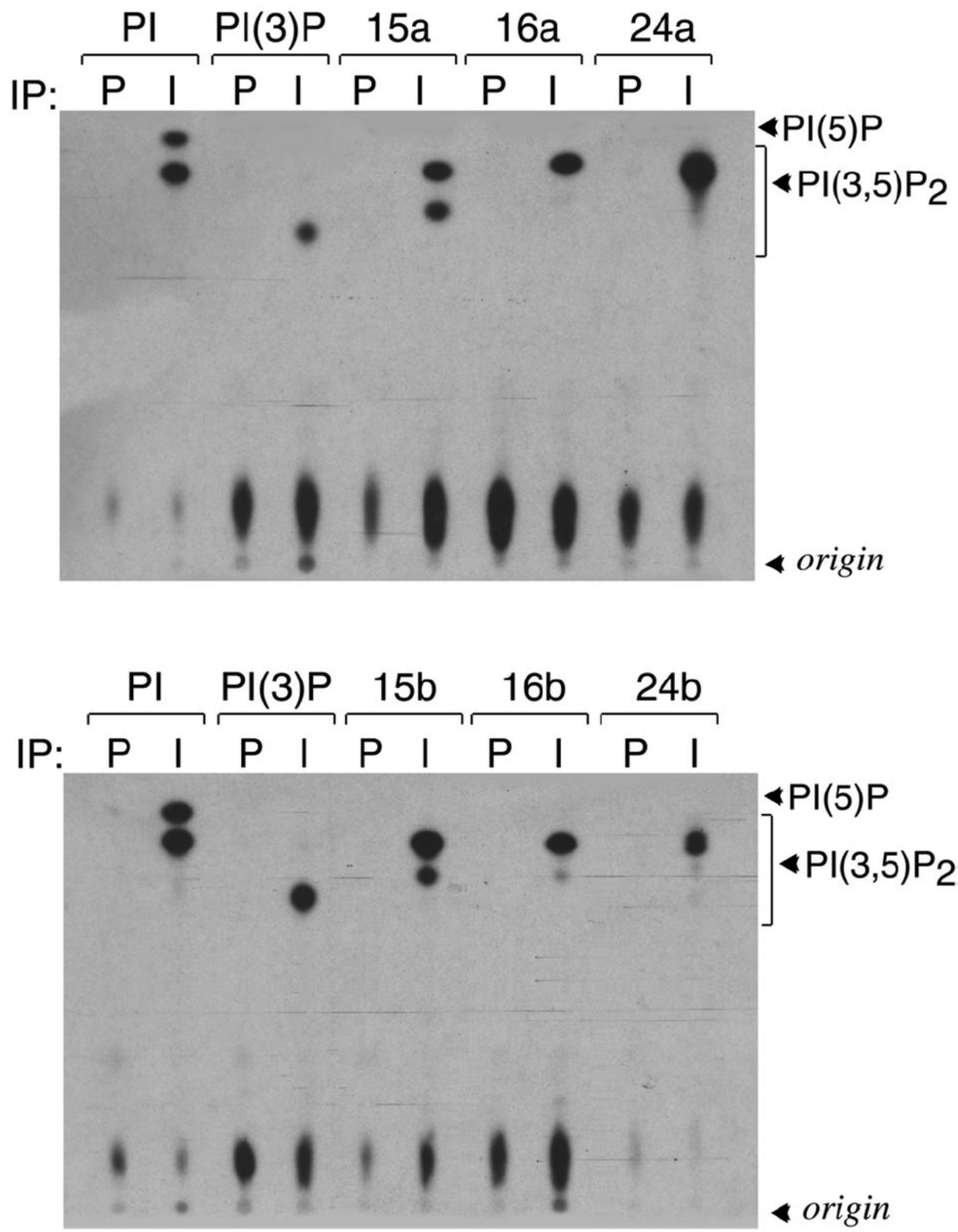

Figure 2.

Radio-TLC shows that PtdIns(3)P analogs are recognized by and phosphorylated by PIKfyve. Refer to experimental section for details. 


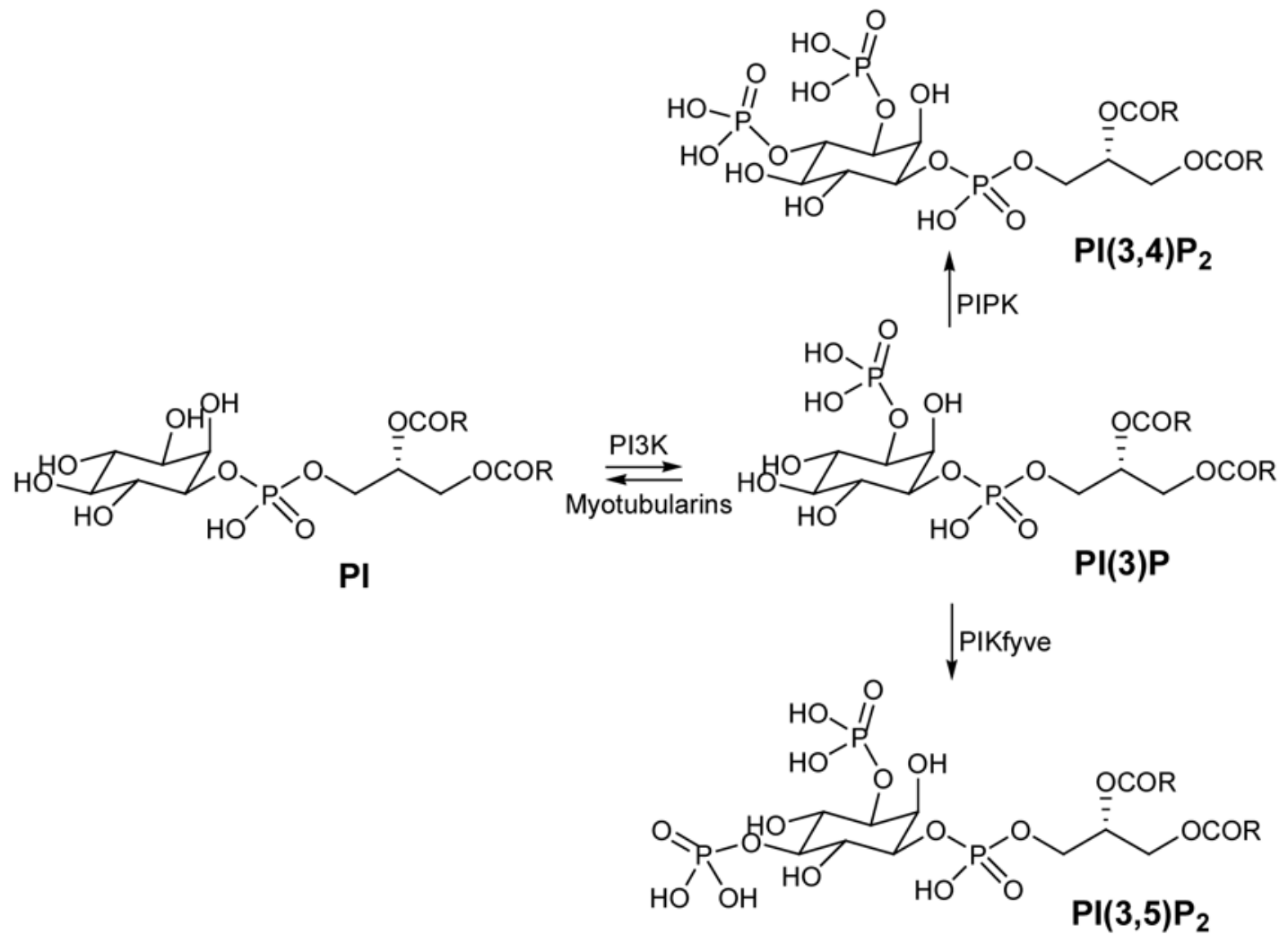

Scheme 1.

Metabolic interconversions of PtdIns(3)P. 

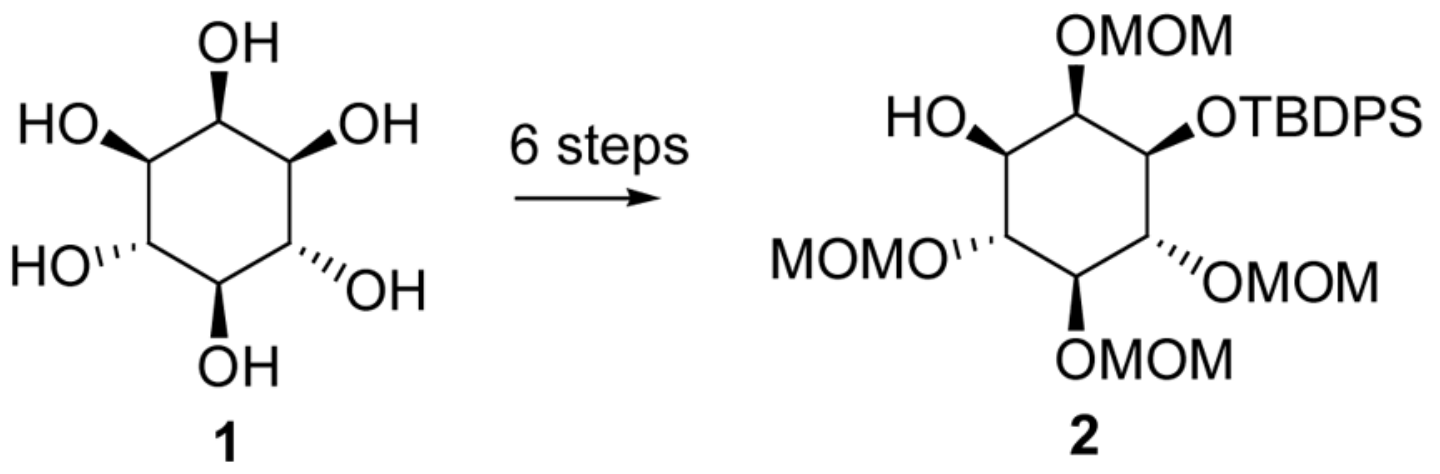

Scheme 2.

Synthesis of enantiomerically-pure D-myo-inositol intermediate. 
<smiles>COP(C)(=O)OCOP(C)(=O)Cl</smiles><smiles>COP(=O)(CO)OCC(C)OP(=O)(OC)OC</smiles><smiles>COP(=O)(CF)OC[C@@H]1C[C@@H]1OP(=O)(Cl)CF</smiles><smiles>COP(C)(=O)OCC(OP(=O)(CF)OC)C(F)(F)F</smiles>

Scheme 3.

Synthesis of (fluoro)methylphosphonate chloride. Reagents and conditions: (a) $\mathrm{PCl}_{5}$, benzene; (b) $\left(\mathrm{CH}_{2} \mathrm{O}\right)_{n}, \mathrm{~K}_{2} \mathrm{CO}_{3}, \mathrm{CH}_{3} \mathrm{OH}$; (c) $\mathrm{Tf}_{2} \mathrm{O}$, 2,6-lutidine, $\mathrm{CH}_{2} \mathrm{Cl}_{2}$; (d) TBAF, THF; (e) $t$ $\mathrm{BuNH}_{2}$; Dowex resin; then (ClCO) $)_{2}, \mathrm{DMF}, \mathrm{CH}_{2} \mathrm{Cl}_{2}$; (f) $n$-BuLi, THF; then Selectfluor; (g) DAST, $\mathrm{CH}_{2} \mathrm{Cl}_{2}$. 


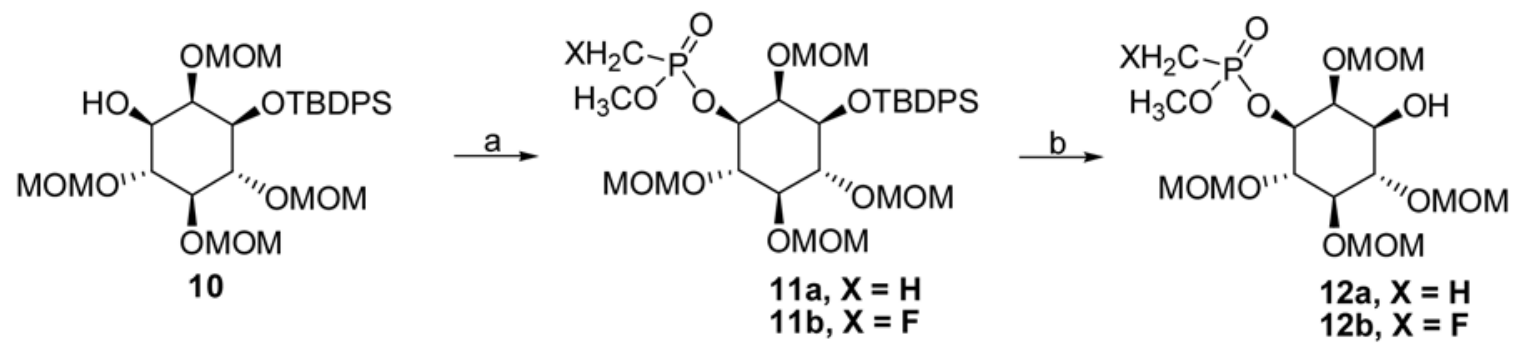

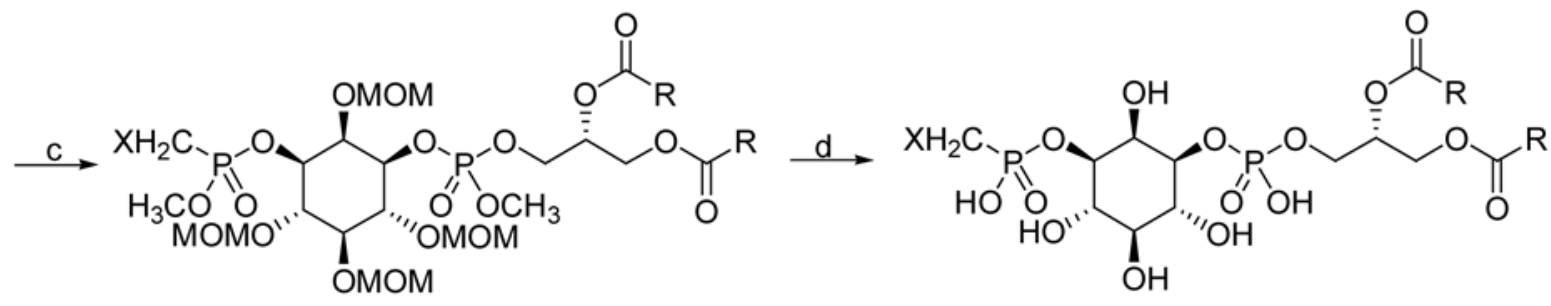

13a, $R=\mathrm{C}_{17} \mathrm{H}_{33}, X=\mathrm{H}$ 13b, $R=\mathrm{C}_{15} \mathrm{H}_{31}, X=\mathrm{H}$ 13c, $R=\mathrm{C}_{3} \mathrm{H}_{7}, X=\mathrm{H}$
$14 \mathrm{a}, \mathrm{R}=\mathrm{C}_{17} \mathrm{H}_{33}, \mathrm{X}=\mathrm{F}$

$14 b, R=C_{15} \mathrm{H}_{31}, X=F$

14c, $R=\mathrm{C}_{3} \mathrm{H}_{7}, X=F$ 15a, $R=\mathrm{C}_{17} \mathrm{H}_{33}, X=\mathrm{H} \quad 16 \mathrm{a}, \mathrm{R}=\mathrm{C}_{17} \mathrm{H}_{33}, \mathrm{X}=\mathrm{F}$ $15 b, R=C_{15} \mathrm{H}_{31}, X=H \quad 16 b, R=C_{15} H_{31}, X=F$ 15c, $R=\mathrm{C}_{3} \mathrm{H}_{7}, X=\mathrm{H}$ 16c, $\mathrm{R}=\mathrm{C}_{3} \mathrm{H}_{7}, X=F$

Scheme 4.

Synthesis of 3-(fluoro)methylphosphonate analogues of PtdIns(3)P. Reagents and conditions: (a) 4 or 9, $t$-BuOK, $\mathrm{CH}_{2} \mathrm{Cl}_{2}$; (b) TBAF- $3 \mathrm{H}_{2} \mathrm{O}, \mathrm{HOAc}$, THF; (c) 19a-19c, $1 H$-tetrazole, THF/ $\mathrm{CH}_{3} \mathrm{CN}$; then $n$ - $\mathrm{Bu}_{4} \mathrm{NIO}_{4}, \mathrm{CH}_{3} \mathrm{CN}$; (d) TMSBr, $\mathrm{CH}_{2} \mathrm{Cl}_{2}$; then $\mathrm{CH}_{3} \mathrm{OH} / \mathrm{H}_{2} \mathrm{O}$; then EtSH. 
<smiles>[R]C(=O)OC[C@H](COP(OC)N(C(C)C)C(C)C)OC([R])=O</smiles>

Scheme 5.

Synthesis of glyceryl phosphoramidites. Reagents and conditions: (a) methyl $\mathrm{N}, \mathrm{N}$ diisopropylchlorophosphoramidite, DIPEA, $\mathrm{CH}_{2} \mathrm{Cl}_{2}$; (b) 2-cyanoethyl- $N, N$ diisopropylchlorophosphoramidite, DIPEA, $\mathrm{CH}_{2} \mathrm{Cl}_{2}$. 


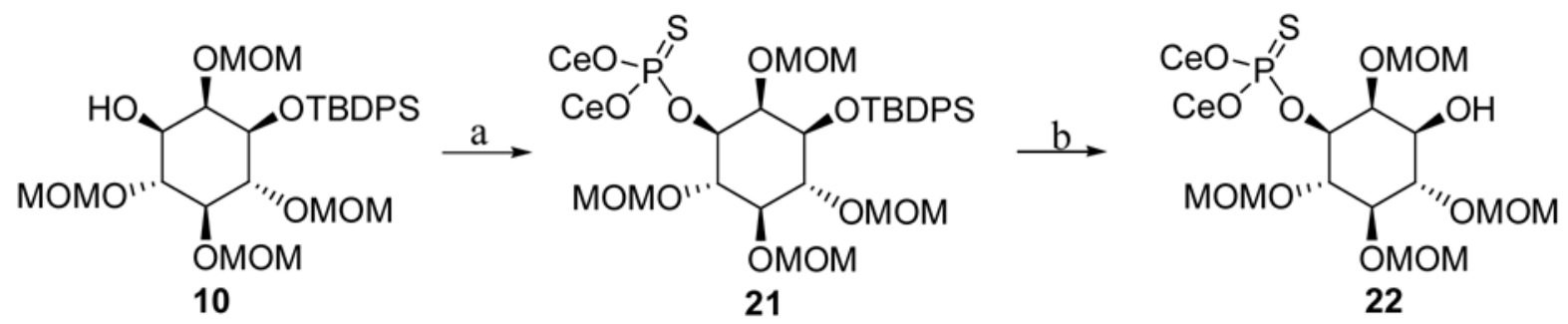

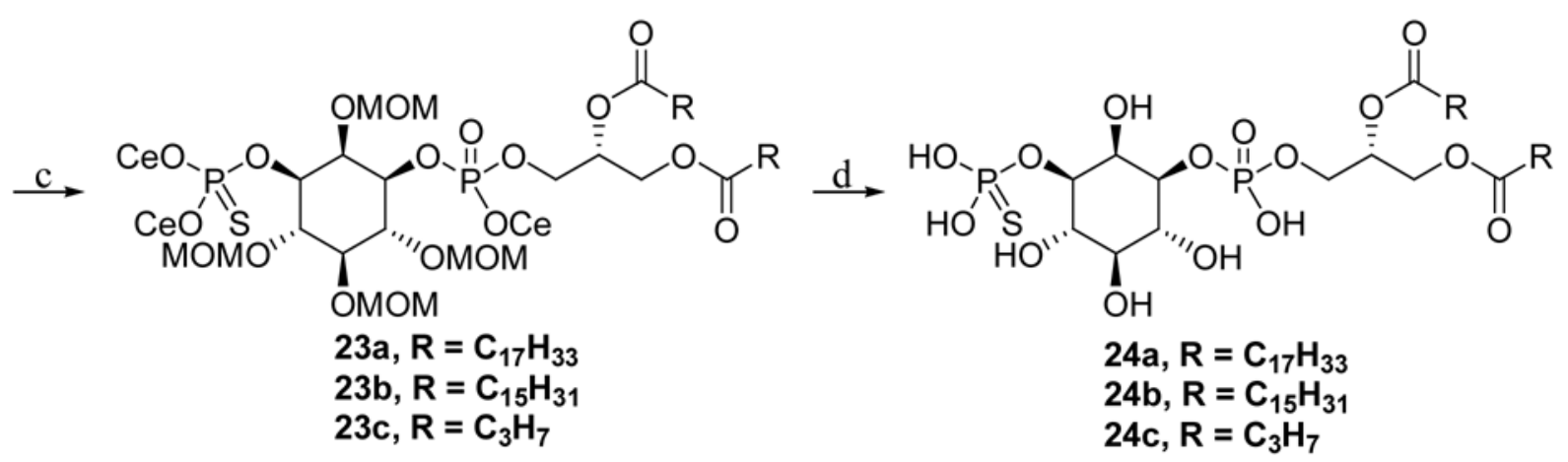

Scheme 6.

Synthesis of 3-phosphorothioate analogues of PtdIns(3)P. Reagents and conditions: (a) di(2cyanoethyl) diisopropylphosphorodiamidite, $1 \mathrm{H}$-tetrazole, $\mathrm{CH}_{3} \mathrm{CN}$; then $\mathrm{S}_{8}, \mathrm{CS}_{2} / \mathrm{Py}$;.(b) HF.Py-Py, THF; (c) 20a-20c, $1 H$-tetrazole, THF/CH ${ }_{3} \mathrm{CN}$; $t$-BuOOH, $\mathrm{CH}_{3} \mathrm{CN}$; (d) TEA, TFBSA, $\mathrm{CH}_{3} \mathrm{CN}$; then $\mathrm{NH}_{4} \mathrm{OAc} / \mathrm{H}_{2} \mathrm{O}$; then $\mathrm{EtSH}, \mathrm{BF}_{3}$. $\mathrm{Et}_{2} \mathrm{O}$. 


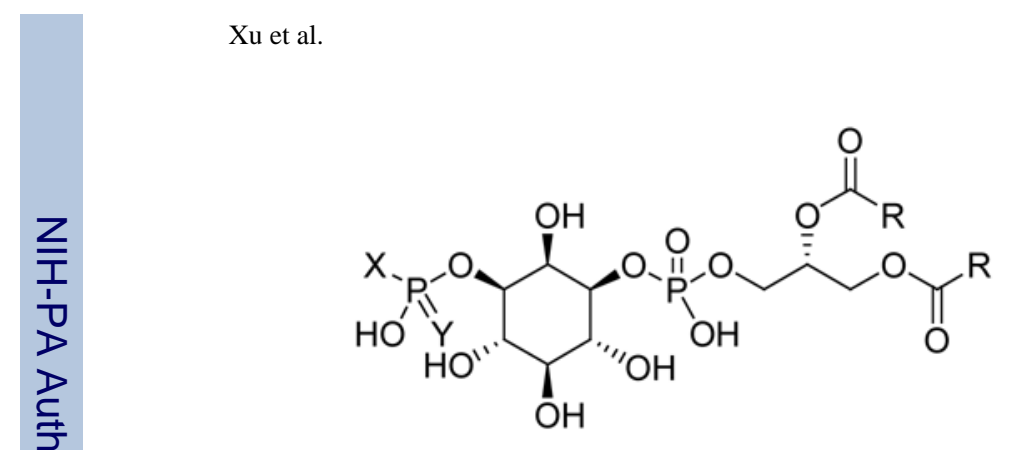

15a, $\mathrm{R}=\mathrm{C}_{17} \mathrm{H}_{33}, \mathrm{X}=\mathrm{H}$

$15 b, R=C_{15} H_{31}, X=H$

16a, $\mathrm{R}=\mathrm{C}_{17} \mathrm{H}_{33}, \mathrm{X}=\mathrm{F}$

16b, $R=\mathrm{C}_{15} \mathrm{H}_{31}, X=F$

24a, $\mathrm{R}=\mathrm{C}_{17} \mathrm{H}_{33}$

24b, $R=\mathrm{C}_{15} \mathrm{H}_{31}$

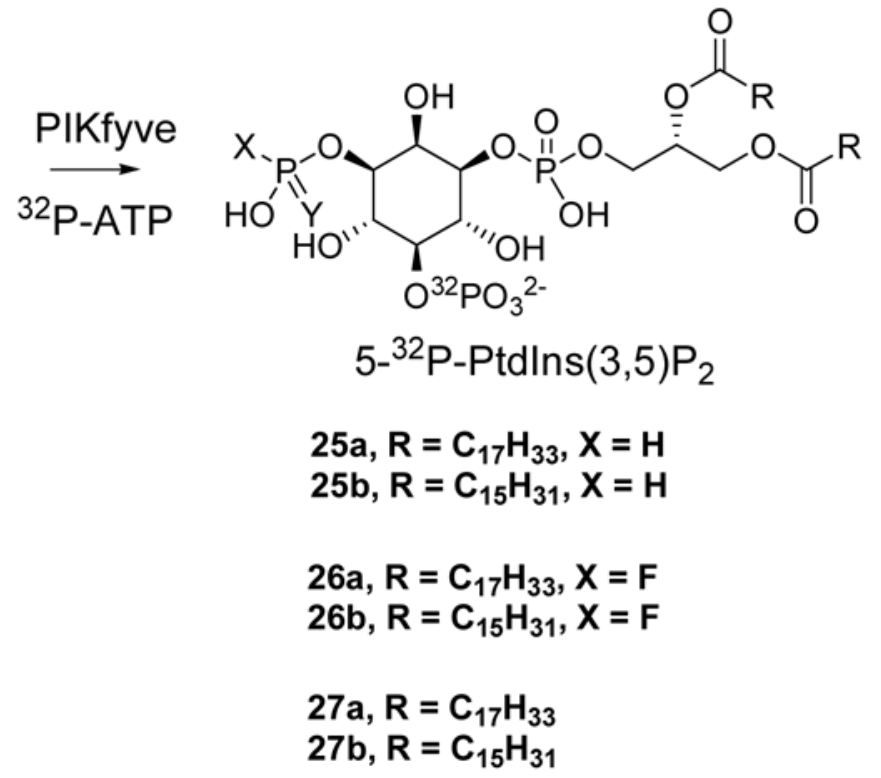

Scheme 7.

Phosphorylation of PtdIns(3)P analogues by PIKfyve. 